This is an Accepted Manuscript of an article published by Taylor \& Francis in "Liquid crystals" on $15^{\text {th }}$ Aug 2016, available online: http://www.tandfonline.com/doi/full/10.1080/02678292.2016.1 218963 


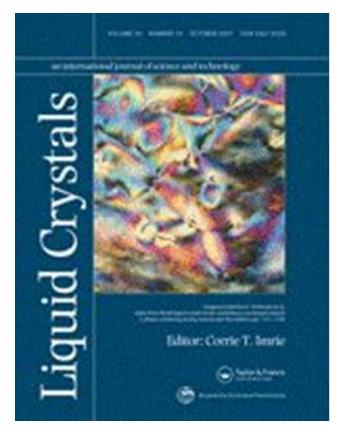

\section{Distinctive dielectric properties of nematic liquid crystal dimers}

\begin{tabular}{|r|l|}
\hline Journal: & Liquid Crystals \\
\hline Manuscript ID & Draft \\
\hline Manuscript Type: & Invited Articles \\
\hline Date Submitted by the Author: & n/a \\
\hline Lomplete of Authors: & $\begin{array}{l}\text { Sebastián, Nerea; Otto von Guericke Universitat Magdeburg, Department } \\
\text { of Nonlinear Phenomena, Institute of Experimental Physics; Universidad del } \\
\text { País Vasco UPV/EHU, Departamento de Física Aplicada II, Facultad de } \\
\text { Ciencia y Tecnología } \\
\text { Robles-Hernández, Beatriz; Universidad del País Vasco UPV/EHU, } \\
\text { Departamento de Física Aplicada II, Facultad de Ciencia y Tecnología } \\
\text { Diez-Berart, Sergio; UPC, Física i Enginyeria Nuclear } \\
\text { Josep, Salud; UPC, Física i Enginyeria Nuclear } \\
\text { Luckhurst, Geoffrey; University of Southampton, Chemistry } \\
\text { Dunmur, David; University of Sheffied, } \\
\text { López, David Orencio; UPC, Física i Enginyeria Nuclear } \\
\text { de la Fuente, Maria Rosario; Universidad del País Vasco, Física Aplicada II, } \\
\text { Facultad de Ciencia y Tecnología }\end{array}$ \\
\hline Keywords: & $\begin{array}{l}\text { liquid crystal dimers, twist-bend nematic phase, dielectric spectroscopy, } \\
\text { molecular conformational distribution }\end{array}$ \\
\hline
\end{tabular}


1

2

3

4

5

6

7

8

9

10

11

12

13

14

15

16

17

18

19

20

21

22

23

24

25

26

27

28

29

30

31

32

33

34

35

36

37

38

39

40

41

42

43

44

45

46

47

48

49

50

51

52

53

54

55

56

57

58

59

60

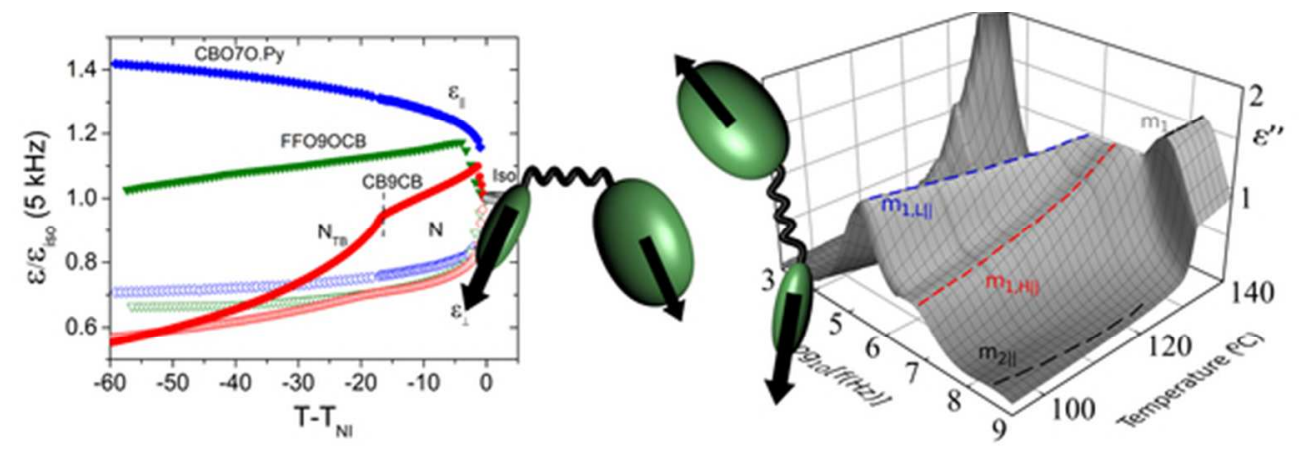

$50 \times 16 \mathrm{~mm}(300 \times 300 \mathrm{DPI})$

URL: http://mc.manuscriptcentral.com/tlct Email: c.t.imrie@abdn.ac.uk 


\section{Distinctive dielectric properties of nematic liquid crystal dimers}

N. Sebastián ${ }^{1,2}$, B. Robles-Hernández ${ }^{2}$, S. Diez-Berart ${ }^{3}$, J. Salud ${ }^{3}$, G. R. Luckhurst $^{4}$, D. A. Dunmur ${ }^{5}$, D. O. López ${ }^{3}$, M. R. de la Fuente ${ }^{2}$

${ }^{1}$ Otto-von-Guericke Universitat Magdeburg, Institute for Experimental Physics, ANP, 39106 Magdeburg, Germany

${ }^{2}$ Departamento de Física Aplicada II, Facultad de Ciencia y Tecnología, Universidad del País Vasco. Apartado 644, E-48080 Bilbao, Spain

${ }^{3}$ Grup de Propietas Físiques dels Materials (GRPFM), Departament de Física, E.T.S.E.I.B. Universitat Politècnica de Catalunya. Diagonal 647, E- 08028 Barcelona, Spain

${ }^{4}$ Chemistry, University of Southampton, Highfield, Southampton, SO17 1BJ, United Kingdom

${ }^{5}$ School of Physics and Astronomy, University of Manchester, Manchester M13 9PL, United Kingdom

Corresponding author: Nerea Sebastián: nerea.sebastian@ehu.eus Maria Rosario de la Fuente: rosario.delafuente@ehu.es

Author Information:

Beatriz Robles-Hernández: beatriz.robles@ehu.eus

Sergio Diez-Berart: sergio.diez@upc.edu

Josep Salud: josep.salud@upc.edu

Geoffrey R. Luckhurst: g.r.luckhurst@ soton.ac.uk

David A. Dunmur: d.dunmur@tiscali.co.uk

David O. López: david.orencio.lopez@upc.edu 


\section{Distinctive dielectric properties of nematic liquid crystal dimers}

We provide an overview of the effect of the molecular structure on the dielectric properties of dimers exhibiting nematic and twist-bend nematic phases with special focus on how the conformational distribution changes are reflected by the dielectric behaviour. Nematic dimers show distinctive dielectric properties which differ from those of archetypical nematic liquid crystals, as for example unusual temperature dependence of the static permittivity or dielectric spectra characterized by two low-frequency relaxation processes with correlated strengths. The interpretation of such characteristic behaviour requires that account is taken of the effect of molecular flexibility on the energetically favoured molecular shapes. The anisotropic nematic interactions greatly influence the conformational distribution. Dielectric behaviour can be used to track those conformational changes due to dependence of the averaged molecular dipole moment on the averaged molecular shape. Results for a number dimers are compared and analysed on the basis of the influence of details of the molecular structure, using a recently developed theory for the dielectric properties of dimers [Dunmur DA, Luckhurst GR, de la Fuente MR, Diez S and Perez Jubindo MA. J.Chem.Phys. 2001;115, 8681 \& Stocchero M, Ferrarini A, Moro GJ, Dunmur DA and Luckhurst GR. J.Chem.Phys. 2004;121, 8079].

Keywords: liquid crystal dimers; twist-bend nematic phase; dielectric spectroscopy; conformation distribution;

\section{Introduction}

It is well-known how rod-shaped [1,2], disk-shaped [1,2,3] and bent-shaped molecules $[4,5]$ induce their own hierarchy of mesophases with different symmetries. Although all these different structures can show a nematic phase, it is expected that the phase behaviour and properties will be greatly influenced by the details of the molecular structure. Of particular interest are liquid crystal dimers, for which the introduction of extra degrees of freedom to the molecular shape by the core flexible spacer has been demonstrated to have a strong impact on their phase behaviour and properties. Calamitic, discotic or bent-core mesogenic groups have been used among others as 
building blocks for dimeric systems, connected by longitudinally or laterally by flexible linking groups of different types, length or parity, and revealing a highly interesting hierarchy of mesomorphic behaviour [6-13]. However, in the recent years the simplest calamitic-calamitic dimers have attracted considerable attention due to the discovery of a novel nematic phase, originally for cyanobiphenyl based odd dimers with methylene links ( $\alpha, \omega$-bis $(4,4$ '-cyanobiphenyl)-alkanes $\mathrm{CBnCB})$. Depending on the chain parity, dimers adopt a preferred linear (even) or a bent (odd) averaged molecular shape, responsible for the pronounced odd-even effect observed on many of their properties, as for example, transitional entropies and temperatures [14-16], dielectric anisotropy values [17], elastic constants and flexoelectric coefficients [17-19]. In the case of the odd bent conformation, the molecular structure does not fit well to the nematic environment causing lower transition temperatures and entropy changes at the isotropicnematic transition $[11,20]$. However, of fundamental interest is the effect molecular curvature exerts on the elastic properties of odd dimers, which causes an inversion of the ratio of the splay and bend elastic constants, with the latter taking remarkable low values and a decreasing tendency with increasing order parameter [18,19,21-25]. It seems that the ultimate consequence of this unique combination of molecular flexibility and bent molecular curvature is the appearance of an additional nematic mesophase, found at temperatures below the conventional nematic phase [23,26-29]. This novel nematic phase has been identified by a wide number of studies as the twist-bend nematic phase $\left(\mathrm{N}_{\mathrm{TB}}\right)$ initially predicted for bent-shaped molecules [30,31] and is characterized by a spontaneous twist-bend deformation of the nematic director. That is, a mesophase with only long-range orientational order where the director tilts and is arranged in a heliconical structure, characterized by a very short pitch of the order of $\mathrm{nm}[23,29,32]$ and a conglomerate of domains having doubly degenerate handedness. 
A variety of molecular field theories have been developed [16,33-36], which include the flexibility of the spacer in the calculation of the conformer distribution and whose primary feature is the way the conformational state of the spacer is described. The Rotational Isomeric State (RIS) model [33] limits the torsional angles of the chain bonds to the three tetrahedral conformations, resulting in the two possible angles between the para axis of the mesogenic units for odd and even dimers which are depicted in Figure 1: for an odd dimer, the all-trans conformation that is bent and the cis conformation that forms a hairpin-shape, while for even dimers, the all-trans conformation is linear and the cis conformation is bent. Although the RIS model allows for a qualitative understanding of the odd-even effect mentioned previously, a realistic description of nematic phases of liquid crystal dimers should account for the flexibility of the spacer and include a wide range of conformations together with its temperature dependent distribution. Ferrarini et al. showed that a continuous distribution of torsional angles around the minima of RIS model [26,35,37] is necessary to explain the behaviour of liquid crystal dimers, including their dielectric properties. For odd dimers and considering a nematic environment, the continuous torsional potential model (CTP) predicts a broad conformational distribution around RIS configurations dominated by bent conformers $\left(\sim 120^{\circ}\right.$ for $\left.\mathrm{CBnCB}\right)$, but with an appreciable contribution of hairpin molecular configurations $\left(\sim 15^{\circ}\right.$ for $\left.\mathrm{CBnCB}\right)$, and anticipates that the increase of orientational order of the para-axis of the mesogenic units is reflected by the stabilization of the extended bent conformers at the expense of the hairpin-shaped ones $[19,26,38]$. Moreover, the continuous torsional potential also predicts a small decrease of the molecular curvature of the bent conformers for higher order parameters in order to better accommodate to the nematic potential. 
In addition to the spacer parity, the molecular curvature 'fine-tuning' effect of the nature of the linking chain should not be disregarded. In fact, while the odd CBnCB molecules constitute the archetypical example of materials exhibiting the $\mathrm{N}_{\mathrm{TB}}$ phase [22,26,27,29], $\alpha, \omega$-bis(4,40-cyanobiphenyloxy)alkanes (CBOnOCB) compounds do not appear to satisfy the necessary conditions, such as the curvature, to avoid crystallization and to show the $\mathrm{N}_{\mathrm{TB}}$ phase [37]. However, the intense work in the field during the last few years revealed the occurrence of $\mathrm{N}_{\mathrm{TB}}$ phases for a variety of etherlinked [24,39], hydrogen-bonded driven [40], imine-linked [28] odd dimers or nonsymmetric odd bimesogens containing chiral units [41,42].

In the case of dimers carrying dipole moments, any conformational change is reflected by the dielectric response, which is a measure of the mean-square dipole moment, understood as the averaged vector sum of the different molecular configurations. Thus, dielectric spectroscopy can reveal information about the temperature dependence of the conformational distribution as well as orientational order, which, as will be shown, is particularly the case for dimers with large longitudinal dipolar groups in the mesogenic units. Dielectric spectroscopy is also a powerful technique to gain insight into the rotational dynamics of the dipolar groups in different orienting environment conditions [43]. In this paper we aim to provide a comprehensive overview of the distinctive dielectric properties of nematic dimers, both for the conventional $\mathrm{N}$ and for the $\mathrm{N}_{\mathrm{TB}}$ phases. Accordingly, we will bring together and compare the most recent results for a number of dimers with different molecular structures in order to demonstrate the effect that chain length or molecular dipole distribution exert on the dielectric behaviour. This contribution will focus on dimers with positive dielectric anisotropy and large longitudinal dipole moments in the semirigid mesogenic groups. Results will be complemented with additional analysis of the 
dielectric and elastic properties of a binary mixture of $\mathrm{CB} 7 \mathrm{CB}+\mathrm{CB} 9 \mathrm{CB}$ and, for the sake of comparison, with the comprehensive analysis of the dielectric properties of the nematic even dimer $\alpha$-(2',4-difluorobiphenyl-4'-yloxy)- $\omega$-(4-cyanobiphenyl-4'yloxy)decane (FFO10OCB). Results will be discussed in the framework of Stocchero et al.'s theoretical model [38] for the dielectric relaxation of nematic dimers, which will be detailed in later sections.

\section{Results}

\subsection{Materials and methods}

The materials considered in this contribution can be classified into two broad groups: symmetric and non-symmetric dimers. Among the former (case i), we will consider the cyanobiphenyl based dimers CB9CB [44] and CB7CB [26], which constitute the most representative examples of liquid crystal dimers exhibiting the $\mathrm{N}_{\text {TВ }}$ phase. The relative orientation of the dipole moments of each of the cyanobiphenyl units ( 4D) will determine the molecular net dipole moment. The schematic molecular structure, dipole distribution and mesomorphic behaviour of both materials is depicted in Figure 2 [26,27,44-46]. In addition, a two component mixture of both symmetric materials $(\mathrm{CB} 7 \mathrm{CB}+\mathrm{CB} 9 \mathrm{CB}$ with 0.46 mole fraction of $\mathrm{CB} 9 \mathrm{CB})$ will also be considered. The mixture was prepared in a sealed aluminium pan and ultrasonicated in the isotropic phase. The observed phase sequence is listed in Figure 2.

On the other hand, two different situations can be recognised for non-symmetric dimers: case (ii) only one mesogenic unit has a dipole moment and case (iii) both semirigid units carry dipole moments but of different magnitude. As an example of the latter, the ether-linked odd FFO9OCB [24] and even FFO10OCB dimers will be examined, for which the difluorobiphenyl unit has two identical dipole moments of about 1.5 D 
associated with the C-F bonds, implying a net longitudinal contribution of about $2.25 \mathrm{D}$ with respect to the para-axis of the mesogenic unit in comparison with the larger dipole ( 4 D) of the nitrile group. FFO10OCB was synthesised according to [24] and the liquid crystal phase behaviour has been characterized using modulated differential scanning calorimetry and polarized optical microscopy observations. The schematic molecular structures and mesomorphic behaviour of both materials are given in Figure 2 $[17,18,24]$. Although only a nematic phase is observed for the even dimer, it has been shown that a monotropic twist-bend nematic phase can be obtained for FFO9OCB at very fast cooling rates. The latest results have shown that the $\mathrm{N}_{T B}$ phase can be stabilized in binary mixtures with CB7CB [47], thus facilitating the study of simple, non-symmetric systems exhibiting a $\mathrm{N}_{\mathrm{TB}}$ phase [48].

Finally, as an illustrative example of case (ii), the behaviour of the family of $\alpha$ (4-cyanobiphenyl-4'-oxy)- $\omega$-(1-pyreniminebenzylidene-4'-oxy)alkanes

(CBOnO.Py) will be explored [49-54]. As shown in Figure 2 these materials consist of two etherlinked terminal groups of greatly different shapes and sizes. The smaller unit, a cyanobiphenyl, has a dipole moment associated with the nitrile group, while the larger unit only carries a very small transverse dipole moment (associated with the imine group) that can be disregarded. Extensive studies have been performed on this family[49-52,54] showing that, excluding the shortest member $(n=3)$ with a monotropic nematic phase, the rest of the odd members $(n=5-11)$ exhibit enantiotropic nematic behaviour. In addition CBO9O.Py, CBO7O.Py and CBO5O.Py show a SmA phase at lower temperatures. Figure 2 gives a schematic representation of the molecular structure, together with the phase sequence for the compounds with $n=7$ and $n=5$.

Measurements of the static permittivity were performed in $8 \mu \mathrm{m}$ thickness Instec cells with antiparallel planar rubbing using the Agilent Precision LRC meter 
E4890A. The perpendicular $\left(\varepsilon_{\perp}\right)$ and the parallel $\left(\varepsilon_{\|}\right)$components with respect to the nematic director were obtained by using harmonic probe electric fields well below ( 0.5 Vrms) and well above (19 Vrms) the threshold voltage of the Fréedericksz transition. Samples were held on a hot stage (TMSG-600) with a temperature controller (TMS-93), both from Linkam. The same setup was used to measure the splay and bend elastic constants by means of the capacitance method for $\mathrm{CB} 7 \mathrm{CB}, \mathrm{CB} 9 \mathrm{CB}$ and their mixture discussed here. A detailed description of the procedure can be found elsewhere [44]. In order to characterize the dielectric spectra of a diversity of materials with very different behaviour our setup includes a number of impedance analyzers (AlphaA from Novocontrol, HP4192A, HP4291A and HP4294), which allows for full adaptability to make measurements over the frequency range $10^{-2}-1.8 \times 10^{9} \mathrm{~Hz}$. An adequate combination of analyzers was employed for each of the materials discussed here as detailed elsewhere $[24,44,46,51,52]$. In the case of FFO10OCB, HP4192A and HP4291A were used to measure the dielectric spectra presented in this paper. The accurate measurement of high frequency spectra requires the utilization of cells with untreated metal electrodes, which in our setup consists of a parallel plate capacitor made of two circular gold-plated brass electrodes with $5 \mathrm{~mm}$ diameter separated by $50 \mu \mathrm{m}$ thick silica spacers. Regardless of the analyzer, the sample is placed at the end of a coaxial line and a modified HP16091A coaxial test fixture was used as the sample holder. The system is held inside a Novocontrol cryostat, which screens it, and the dielectric measurements were performed on cooling with the different temperature steps being stabilized to $\pm 20 \mathrm{mK}$. In every case, the spectra has been analyzed for each temperature according to the Havriliak-Negami function through the empirical relationship, 


$$
\varepsilon(\omega)-\varepsilon_{\infty}=\varepsilon^{\prime}(\omega)-i \varepsilon^{\prime \prime}(\omega)=\sum_{k} \frac{\Delta \varepsilon_{k}}{\left[1+\left(i \omega \tau_{k}\right)^{\alpha_{k}}\right]^{\beta_{k}}}-i \frac{\sigma_{d c}}{\omega \varepsilon_{0}}
$$

where $\varepsilon_{\infty}$ is the extrapolated high frequency permittivity, $\sigma_{d c}$ is the dc conductivity and the sum is extended over the different relaxation modes with strengths $\Delta \varepsilon_{k}$. The relaxation time is related to the frequency of maximum loss through the parameters $\alpha$ and $\beta$, which describe the width and the asymmetry of the relaxation spectra, respectively ( $\alpha=\beta=1$ corresponds to a simple Debye-like process).

\subsection{Static permittivity}

\subsubsection{Effect of dipolar structure.}

The comparison between the temperature dependence of the static dielectric permittivity for the three dimers CB9CB [44], FFO9OCB [24] and CBO7O.Py [52] yields an interesting overview of the contrasting dielectric behaviour exhibited by nematic dimers as a result of the different molecular structures. Permittivity data reduced by the permittivity value at the isotropic phase $\varepsilon_{i s o}\left(T_{N I}\right)$ is gathered and plotted in Figure 3 as a function of the shifted temperature $\left(\mathrm{T}-\mathrm{T}_{N I}\right)$ for the three compounds. One conclusion that can be drawn at first glance is: while the molecular structure does not greatly influence the temperature dependence of the perpendicular component of the permittivity $\left(\varepsilon_{\perp}\right)$, the behaviour of the parallel component $\left(\varepsilon_{\|}\right)$drastically depends on it. This directly reflects the fact that the different molecular dipolar configurations will dictate the mean square longitudinal dipole moment through the conformational distribution changes and so, will give rise to a wide diversity of behaviours. For CBOnO.Py-like structures (ii), conformational changes do not affect the mean averaged longitudinal dipole moment given just by the single nitrile group and accordingly, $\varepsilon_{\|}$ 
behaves as typical liquid crystal monomers with positive dielectric anisotropy. In the contrasting case we find symmetric dimers like $\mathrm{CB} 9 \mathrm{CB}$, for which molecular conformational changes introduce a strong temperature variation of $\varepsilon_{\|}$. Such variation results increasing difference between the extrapolated value at the isotropic phase and the mean permittivity value in the nematic phase, which indicates a strong reduction of the mean-square dipole moment as the temperature is lowered. Due to symmetry reasons, for odd dimers the bent molecular configurations (trans conformers) have no longitudinal dipole moment if the angle between the terminal dipoles is greater than $90^{\circ}$ and their contribution to the orientational dielectric permittivity will be null. However, hairpin conformers with small interarm angles, for which both rigid units tend to align on average along the director, greatly contribute to the parallel component of the permittivity. Thus, the strong decrease of $\varepsilon_{\|}$on reducing the temperature reflects the progressive increase of the population of the bent (trans) molecular conformers, which are accommodated better by the nematic potential. We recall here, that the permittivity increases at the onset of the nematic order, which is agreement with molecular calculations [38] and corresponds to an initial stabilization of the hairpin conformers at the isotropic to nematic transition. Another interesting observation for $\mathrm{CB} 9 \mathrm{CB}$ is that through the nematic and twist-bend nematic phases the dielectric anisotropy continuously decreases from a relative high value to even small negative at temperatures far from the nematic-nematic transition. The picture is then completed with the behaviour of FFO9OCB (case iii). Although $\varepsilon_{\|}$still decreases with the increase of the orientational order, as for the symmetric $\mathrm{CB} 9 \mathrm{CB}$, such decrease is much less pronounced. In this case the non-symmetry on the dipolar structure of both mesogenic units implies a non-zero longitudinal dipole component even for bent molecular configurations, which is responsible for the intermediate behaviour shown by this 
nematic dimer.

On the other hand, the behaviour of $\varepsilon_{\perp}$ is determined by the temperature dependence of the averaged transverse dipole moment, for which the differences between bent and hairpin conformers are more subtle and so, comparison of these three highly different materials is challenging. However, it is worth considering here the latest results for a series of binary mixtures of CB7CB and FFO9OCB $[47,48]$. The stabilization of the $\mathrm{N}_{\mathrm{TB}}$ phase even for low mole fractions CB7CB allowed for the observation of the behaviour of $\varepsilon_{\perp}$ at the $\mathrm{N}-\mathrm{N}_{\mathrm{TB}}$ transition in the presence of a non-zero longitudinal dipole moment contribution. It has been shown that for the different mixtures with $\mathrm{CB} 7 \mathrm{CB}$ mole fractions up to 0.82 there is a slight increase of $\varepsilon_{\perp}$ at the $\mathrm{N}-\mathrm{N}_{\mathrm{TB}}$ transition which, as will be also discussed in the following sections, can be explained by the sudden contribution of the longitudinal dipole moment occurring at the onset of the heliconical tilt structure of the twist-bend nematic phase.

\subsubsection{Effect of chain length and parity.}

Figure 4.a collects the static permittivity data of $\mathrm{CB} 7 \mathrm{CB}$ and $\mathrm{CB} 9 \mathrm{CB}$, together with that of their mixture with a mole fraction of CB9CB equal to 0.46 . Although as expected the three samples show a similar behaviour, there is still an appreciable and interesting difference in their value. Comparing the two pure compounds, it is clearly observed that the longer $\mathrm{CB} 9 \mathrm{CB}$ shows higher $\varepsilon_{\|}$and lower $\varepsilon_{\perp}$, resulting in larger anisotropy values for the same dipolar molecular structure. At the same time, the binary mixture shows an intermediate behaviour. These subtle differences can be tentatively explained in terms of the combined influence of two effects. First, it is expected that for longer chains both mesogenic units can behave more independently allowing for a slightly higher proportion of hairpin-shaped conformations with high longitudinal dipole moment. 
Second, for longer chains the addition of small displacements in the torsional angles together with the strong preference for the semi-rigid units to tend to align with the director, promotes hairpin and bent conformational angles that adjust better to the nematic ordering and thus, an averaged lower transverse dipole moment [55]. Interestingly, the trend in the dielectric anisotropy is directly reproduced by the values of the splay and bend elastic constants as can be appreciated in Figure 4.b. The longer homologue presents larger values of $K_{1}$ and $K_{3}$ than those of CB7CB, while the values for the mixture fall between the two pure compounds. The small but somewhat larger increase of $K_{3}$ close to the I-N transition could be explained by the slightly larger population of hairpin conformers. On further cooling, $K_{3}$ decreases and takes values as low as $0.4 \mathrm{pN}$ close to the $\mathrm{N}-\mathrm{N}_{\mathrm{TB}}$ transition for the three materials. Values reported here are in good agreement with those obtained by different experimental methods reported in literature $[18,21,25]$.

Finally, comparison of the dielectric behaviour for the two consecutive homologues FFO9OCB [24] and FFO10OCB is shown in Figure 5. An opposite effect is clearly observed for these two consecutive odd and even dimers. Although having a longer chain, both reduced components of the permittivity of FFO10OCB are smaller. This results in a smaller anisotropy for the even dimer, with measured values of 2.7 for FFO10OCB and 3.2 for FFO9OCB at $10{ }^{\circ} \mathrm{C}$ below the $\mathrm{I}-\mathrm{N}$ transition, in good agreement with the trend reported for the homologues with $n=5$ to 12 [17].The difference in value of $\varepsilon_{\|}$could be tentatively explained by the combined effect of a higher percentage of trans conformers for the even dimer (as will be discussed in the next section) and of the comparable smaller mean averaged molecular dipole moment of the cis conformers for the even dimer with respect to the odd one (see Figure 2). In addition the increase of the orientational order also entails a larger increase of the most 
elongated conformers for FFO10OCB, but in this case with relative angles closer to $180^{\circ}$. This implies a reduction of the averaged transverse dipole moment with respect to the odd dimers and, as can be observed in Figure 5, this is reflected by the lower $\varepsilon_{\perp}$ values.

\subsection{Dielectric spectrum}

\subsubsection{Molecular theory of dielectric relaxation in nematic dimers.}

As has been shown in the preceding section, equations for the static permittivity components obtained by Maier and Meier for rigid rod-shaped mesogenic molecules in a nematic potential [56] fail to describe completely the variety of behaviours that are observed for flexible dimers. In addition, measurement of dielectric absorption curves of the non-symmetric dimer CB.O9O.10 [57] showed two well-defined Debye-like absorptions at frequencies characteristic for end-over-end relaxations instead of the single relaxation expected by Nordio-Rigatti-Segre (N-R-S) equations for dielectric relaxation in nematic liquid crystals composed of rigid rod-like molecules [58]. These findings motivated Stocchero et al. [38] to develop a theory for the dielectric relaxation of nematic dimers for which each of the mesogenic units is subjected to a nematic potential resulting in a four-state generalization of the Maier-Saupe potential $[59,60]$. The authors assumed a well defined time separation between chain dynamics and the reorientational relaxation processes and, due to the nature of the potential, state that orientational relaxation occurs via individual (note but not independent) end-over-end reorientation of the rigid units. It should be noted here, that flexible spacer imposes a correlation between both mesogenic units, accounted for by the equilibrium conformational distribution, which implies that the reorientaitons are considered to be individual but not independent. The flipping of the whole molecule at a time is excluded 
because it corresponds to the passage over a large potential barrier. A schematic representation of the interconversion processes between the four stable predicted states is given in Figure 6. Relative reorientation rates $k_{i}^{C \rightarrow T}$ and $k_{i}^{T \rightarrow C}$ for each unit are determined by the rotational diffusion coefficients and the corresponding energy barriers, while relative equilibrium populations of the cis/trans states will dictate the relaxation strengths. It is expected that different dimeric structures will result in very different dielectric dispersion profiles with unique characteristics. The next sections present a summary of the particular cases applicable to the materials considered in this paper.

\subsubsection{Equivalent mesogenic units.}

For dimers composed of two identical mesogenic units with a non-zero longitudinal dipole moment, the kinetic model is simplified and the following monoexponential decay is predicted for the dipole correlation function in order to describe the low frequency dispersion of the parallel component of the permittivity [38]

$$
C_{\|}(t)=4\left\langle\mu_{\|}\right\rangle^{2} P_{C}^{e q} \exp \left(-2 k^{C \rightarrow T} t\right)
$$

where $\left\langle\mu_{\|}\right\rangle$is the average longitudinal dipole moment located in each of the rigid units and $P_{C}^{e q}$ is the equilibrium population of the cis conformers. This correlation function implies an absorption profile characterized by a single relaxation process whose strength is determined by the population of cis conformers, i.e. hairpin conformers for odd dimers. Such prediction successfully interprets the dielectric parallel spectra reported for the nematic phases of $\mathrm{CB} 9 \mathrm{CB}$ [44], CB7CB [26] or CBO11OCB [57] dimers, which show a low frequency relaxation mode $\left(m_{1 \|}\right)$ whose strength diminishes 
when lowering the temperature, or equivalently, decreases with increasing orientational order and decreasing population $P_{C}^{e q}$. In all cases an additional higher frequency mode $\left(m_{2 \|}\right)$ is also detected with smaller strength that can be associated with the fast equilibration precessional and orientational motions (around the molecular long axis) of the dipolar groups within the potential wells. The same dielectric modes are present for the perpendicular component of the permittivity, although in this case that at higher frequency $\left(m_{2 \perp}\right)$ dominates over the temperature range of the conventional nematic phase with just a small contribution from $m_{1 \perp}$ which can be attributed to a very low amount of director misalignment in the planar configuration. To illustrate this behaviour, Figure 7 recalls the frequency and temperature dependence of the dielectric losses of $\mathrm{CB} 7 \mathrm{CB}$ for the homeotropic (Figure 7a) and planar (Figure 7b) director alignments [46].

Such plots illustrate several couple of remarkable observations that can be made regarding the behaviour of the dielectric properties at the $\mathrm{N}-\mathrm{N}_{\mathrm{TB}}$ transition. Characteristic frequencies of the two modes experience only a slight change at the transition and their activation energies remain almost unaltered [44,46]. This absence of significant changes in the kinetic rates at the phase transition indicates that the difference between the nematic and twist-bend nematic molecular environment does not modify to any great extent the diffusion coefficients and the energy barriers for the reorientational motions of the semi-rigid units. Additionally, CB7CB case is a special case as it exhibits a glassy $\mathrm{N}_{\mathrm{TB}}$ phase which is easily accessible by slow cooling rates. It has been shown that, on approaching the glass transition temperature, both molecular motions become strongly cooperative changing in a concerted manner, both of them being responsible for a single glass transition temperature [46]. Finally, as can be seen 
in Figure 7a, at the $\mathrm{N}-\mathrm{N}_{\mathrm{TB}}$ transition there is a sudden increase of the strength of $m_{1 \perp}$, that is, the emergence of the contribution of the averaged longitudinal dipole moment. This implies the appearance at the transition of a molecular tilt, which is consistent with the heliconical director distribution proposed for the $\mathrm{N}_{\text {TВ }}$ phase. Assuming that the order parameter change is small at the transition, so its effect can be neglected, and that the described increase of $\Delta \varepsilon_{m 1, \perp}$ close to the $\mathrm{N}-\mathrm{N}_{\mathrm{TB}}$ transition arises only due to the molecular director tilt, an estimation of the tilt angle can be calculated from the ratio between $\Delta \varepsilon_{m 1, \perp}$ and $\Delta \varepsilon_{m 1, \|}$ resulting in around $30^{\circ}$ in the case of both, CB7CB and CB9CB [44]. Such estimated values are in the range of other reported values obtained with other techniques [61-64].

\subsubsection{Non-equivalent mesogenic units.}

In the case of dimers composed of non-equivalent mesogenic units Stocchero et al.'s model predicts a richer hierarchy of dielectric absorption profiles with a more complex behaviour, which will ultimately depend on the relative strengths of the longitudinal dipole moments of the two terminal unit. When considering compounds for which only the mesogenic unit with the higher flipping rate has a longitudinal dipole moment (case ii: the highly non-symmetric CBOnO.Py dimers) and assuming a large value of the ratio between the rate coefficients for both rigid units, Stocchero et al's model [38] yields the following correlation function for the low frequency dispersion of the parallel component of the permittivity

$$
C_{\|}(t)=\left\langle\mu_{\|}\right\rangle_{C N}^{2}\left(P_{T}^{e q}-P_{C}^{e q}\right)^{2} \exp \left(-2 k_{B} t\right)+4\left\langle\mu_{\|}\right\rangle_{C N}^{2} P_{T}^{e q} P_{C}^{e q} \exp \left(-2 k_{A} t\right)
$$

where $P_{C}^{e q}$ and $P_{T}^{e q}$ are the relative equilibrium populations of the hairpin (cis) and bend 
(trans) conformers at each temperature and $k_{A}$ and $k_{B}$ are the effective rates of the flipping motions for the fast units and the slow units, respectively. Such a correlation function implies a low frequency dielectric spectrum dominated by two relaxations whose strengths will be determined by the conformational distribution: that of the fast relaxation will decrease with increasing order parameter, while that of the slow relaxation will increase. It is clear, that the combined intensity of both modes would remain constant as shown by the static behaviour described in the previous section. Both relaxation processes can be related to two kinetic processes: the high frequency mode involves the end-over-end rotation of the smaller group, while that at low frequencies implies the flip-flop motion of the larger pro-mesogenic unit, which although does not have a longitudinal dipole moment drives an immediate subsequent transition of the smaller rigid unit to restore the equilibrium population distribution.

The adequacy and possibilities of the model have been discussed in detail for the odd CBOnO.Py $(n=3-11)$ homologues [51,52]. In all cases the dielectric spectra was characterized by two low frequency Debye-like relaxations with correlated strengths $\left(m_{1, L \|}\right.$ and $\left.m_{1, H \|}\right)$, as given by Equation 3, and completed by a slightly broader high frequency relaxation mode $m_{2 \|}$ whose strength decreases with temperature, which is attributed to the superposition of the rotation of the molecule around its long axis and the precessional motions of the rigid units. As an example, the strength and frequency of the relaxation processes for CBO5O.Py are given in Figure 8. As a result of the simplicity of the molecular dipole geometry and of the correlation function, the ratio of the strengths of both modes could be applied straightforwardly to estimate and compare the temperature dependence of the conformational distribution through Equation 3. Calculations of such conformational distributions for the CBOnO.Py homologues have shown that the population of bent conformers increases on lowering the temperature, 
and have confirmed that the shorter the spacer, the higher is the percentage of bend conformers immediately at the I-N transition [52]: around $77 \%$ for the longer CBO11O.Py and 93\% for the shorter CBO3O.Py. In addition, such differences between the conformational distributions as a function of the spacer length give rise to the remarkable appearance of two isotropic relaxation processes associated with the longitudinal dipole moment for the shorter homologues. Both RIS and CTP agree that in contrast to what happens for even dimers, in the case of odd dimers the conformational distribution changes only slightly from the isotropic to the nematic phase. In this way, the lower frequency mode with strength proportional to $P_{T}^{e q}-P_{C}^{e q}$ can be distinguished even in the isotropic phase $\left(m_{1, L}\right)$ for the shorter members (CBO5O.Py and CBO3O.Py), as shown in Figure 8 for CBO5O.Py [52]. Additionally, such dependence of the conformational distribution on the length of the linking spacer also influences the character of the N-I phase transition. It has been shown, that the shorter the flexible chain is, the weaker the first order transition is, pointing out that, molecular biaxiality has a greater impact than molecular flexibility when driving the first order transition to become weaker [54], as is also seen for more conventional dimers [37].

We can now consider the cases of FFO9OCB and FFO10OCB, with an approximate ratio of 1 to $1 / 2$ for the longitudinal dipoles of the cyanobiphenyl and the difluorobiphenyl units, respectively. It has been shown for FFO9OCB that irrespective of the smaller inequivalence in size of both rigid units, the flipping rates time separation is large enough to give a dielectric absorption profile characterized by two low frequency relaxation processes as in the preceding case [24]. Due to the higher transition temperatures, even dimers have usually been ignored for detailed property studies. An interesting way of demonstrating that the distinctive low frequency relaxation mode results from the relative freedom of the rigid units and not from any 
effect that could be introduced by the bent molecular shape of odd dimers, is by comparing the spectrum of the two consecutive homologues FFO9OCB and FFO10OCB. Figure 9 shows the three-dimensional plot of the dielectric losses as a function of temperature and frequency for the even dimer in parallel director alignment, which was obtained by applying a bias electric field of $0.8 \mathrm{~V} / \mu \mathrm{m}$. At first glance, it can be seen that it is comparable to that of the odd dimer reported in [24], with two low frequency relaxation modes together with a third process at higher frequencies $m_{2 \|}$, and with lower strength that again can be attributed to fast equilibration modes due to the chain's torsional dynamics. However, additional information can be obtained from a more detailed inspection.

Stocchero et al.'s model has been adequately adapted to the present case by assuming $\left\langle\mu_{\|}\right\rangle_{C N} \approx 2\left\langle\mu_{\|}\right\rangle_{F F}$ (detail of this can be found in [24]), obtaining the two exponential correlation function

$$
C_{\|}(t)=\frac{1}{4}\left\langle\mu_{\|}\right\rangle_{C N}^{2}\left(P_{T}^{e q}-3 P_{C}^{e q}\right)^{2} \exp \left(-2 k_{B} t\right)+4\left\langle\mu_{\|}\right\rangle_{C N}^{2} P_{C}^{e q} P_{T}^{e q} \exp \left(-2 k_{A} t\right)
$$

where, again, $k_{A}$ and $k_{B}$ are the effective rates of the flipping motions for the fast unit (with $\mathrm{CN}$ ) and the slow unit (with $\mathrm{FF}$ ), respectively. In a similar way to the preceding case, both exponential decays imply two relaxations in the dielectric absorption profile that can be associated with the flip-flop motions of the cyanobiphenyl unit at higher frequencies $\left(m_{1, H \|}\right)$ and the flip-flop motions of the difluorobiphenyl unit at lower rates $\left(m_{1, L \|}\right)$. It becomes evident that, in contrast to Equation 3, the combined intensity of both contributions does not remain constant, but decreases with temperature as $\left(9 / 4-2 P_{T}^{e q}\right)$. As shown in the Figure 10, dielectric spectrum of FFO10OCB was fitted to Equation 1 taking into account three contributions: two Debye-like of lower 
frequencies $\left(m_{1, L \|}\right.$ and $\left.m_{1, H \|}\right)$ and one Cole-Cole $(\alpha=0.82 \beta=1)$ mode at high frequencies $\left(m_{2 \|}\right)$. The temperature dependence of the dielectric strengths of the parallel component, obtained by fitting to Equation 1, is shown in Figure 11 for both homologues. As can be observed, the changes in the conformational distribution determine the behaviour of $\Delta \varepsilon_{m 1, L \|}$ and $\Delta \varepsilon_{m 1, H \|}$, reflecting the increase of trans conformer population (bent shape for odd dimers and linear for the even ones) by the dependencies $1 / 4\left(P_{T}^{e q}-3 P_{C}^{e q}\right)^{2}$ and $4 P_{C}^{e q} P_{T}^{e q}$, respectively. However, a closer examination reveals a different behaviour close to the isotropic to nematic transition, evidencing dissimilar conformational distribution changes at the onset of the nematic ordering.

The temperature dependence of the characteristic relaxation frequencies associated with each mode for both materials are given in Figure 12 as an Arrhenius plot. Calculated activation energies for the two low frequency relaxations associated with the end-over-end rotation of the mesogenic units are $100 \mathrm{~kJ} \mathrm{~mol}^{-1}\left(m_{1, L \|}\right)$ and $63 \mathrm{~kJ}$ $\mathrm{mol}^{-1}\left(m_{1, H \|}\right)$ for FFO10OCB and $90 \mathrm{~kJ} \mathrm{~mol}^{-1}\left(m_{1, L \|}\right)$ and $65 \mathrm{~kJ} \mathrm{~mol}^{-1}\left(m_{1, H \|}\right)$ for FFO9OCB [24]. The ratio of these two activation energies is about 0.6 and 0.7 for the even and odd dimers, respectively, a value to some extent lower than that found for CBOnO.Pys [52] and the non-symmetric dimer CBO9O.10 [57]. In any case, all of the activation energy values found for these dimers are in the same range as those observed for end-over-end reorientation in calamitic nematic phases [65]. Concerning the fast equilibration mode $m_{2 \|}$, the activation energy for both homologues is about $35 \mathrm{~kJ} \mathrm{~mol}^{-1}$, in the same range as found for CBOnO.Py dimers for the same relaxation process [51,52]. 
Most recent results have shown that the stability of the $\mathrm{N}_{\mathrm{TB}}$ phase can be enhanced in mixtures $[21,47,66]$ and that such strategy is successful in achieving the modulated nematic phase at room temperature [21,67]. Thus, to conclude the overall picture of dielectric properties of nematic dimers, it would be interesting to recall the latest results for binary mixtures of FFO9OCB and $\mathrm{CB} 7 \mathrm{CB}$ having different mole fractions [47] as the stabilization of the $\mathrm{N}_{\mathrm{TB}}$ phase allowed for the development of a thorough investigation of the dielectric properties of a system containing a nonsymmetric dimer and exhibiting the twist-bend nematic phase. The analysis of the results for the mixture with mole fraction of $\mathrm{CB} 7 \mathrm{CB}$ equal to 0.48 [48] has shown that in mixtures containing a component with a non-symmetric dipolar distribution, the dielectric spectrum of both, the nematic and the twist-bend nematic phases, shows the two distinctive low frequency dielectric modes of the non-symmetric dimer and a strength ratio between the two modes reflecting the composition of the mixture. In the case studied, both modes can be labelled and associated to the same orientational relaxation process as in the pure FFO9OCB. As previously discussed for symmetric dimers, the frequencies of the three characteristic processes remain almost unaltered at the transition to the $\mathrm{N}_{\mathrm{TB}}$ phase and with practically no change in their activation energies.

\section{Summary}

The present paper provides a survey of the latest studies of the dielectric properties of liquid crystal dimers. As has been discussed, the dielectric behaviour is especially sensitive to molecular shape and flexibility, and liquid crystal dimers are particularly good examples of this. It has been shown how, irrespectively of the molecular dipole geometry or the length and parity of the spacer, the dielectric permittivity reflects the temperature dependence of the conformational distribution, evidencing the increase of 
the population of extended conformers (trans) with decreasing temperature.. In case of the $\mathrm{CBnCB}$ symmetric dimers the increase of trans conformers implies a continuous reduction of the molecular mean-square dipole moment with increasing orientational order, resulting in the steady decrease of the dielectric anisotropy value. Such decrease becomes more pronounced in the $\mathrm{N}_{\mathrm{TB}}$ phase where the director tilts and, for low enough temperatures, the dielectric anisotropy even becomes negative.

With respect to the frequency dependence of the dielectric spectra, liquid crystal dimers are uniquely rich in the variety of different behaviours that can be obtained depending on the molecular structure. Certain non-symmetric dimers show a spectra exhibiting three distinctive processes, with the strengths of the two low frequency dielectric absorptions correlated and dependent on the conformational distribution. Estimation of the dependence of the conformational population on the length of the flexible chain shows that for a family of odd homologues, the proportion of bent conformers increases with decreasing spacer length. When flipping rates of both units are equivalent as for $\mathrm{CBnCB}$ dimers, a two peak profile is recovered for the dielectric spectra. Measurements show that the same molecular processes are obtained for both nematic phases. Regardless of the compound, the tilting of the director at the $\mathrm{N}-\mathrm{N}_{\mathrm{TB}}$ transition results in a sudden increase of the contribution of the reorientation of the mesogenic units to the perpendicular component of the permittivity which can be unambiguously detected in the dielectric spectrum. One key observation is that the relaxation frequencies and their temperature dependence remain practically unchanged at the $\mathrm{N}-\mathrm{N}_{\mathrm{TB}}$ transition. This highlights that, from the dielectric point of view, the nematic or twist-bend nematic molecular environment does not change significantly. To conclude, the latest results for the binary mixture of CB7CB and FFO9OCB illustrates the fact that when increasing the number of components in a dimeric mixture, the 
dielectric behaviour correspondingly becomes more intricate and thus, by the convenient choice of components a wide diversity of dielectric properties can be tailored.

\section{Acknowledgements}

This work was supported by MINECO project MAT2015-66208-C3-2-P. The authors also acknowledge the recognition from the Generalitat de Catalunya of GRPFM as Emergent Research Group (2009-SGR-1243). N.S. thanks the Alexander von Humboldt Foundation for a Postdoctoral Research Fellowship.

References

1. Goodby JW, Collings PJ, Kato T, Tschierske CJ, Gleeson H. y Raynes P. editors. Handbook of Liquid Crystals. Nematic and Chiral Nematic Liquid Crystals. Volume 3. Wiley-VCH Verlag; 2014.

2. Goodby JW, Collings PJ, Kato T, Tschierske CJ, Gleeson H. y Raynes P. editors. Handbook of Liquid Crystals. Smectic and Columnar Liquid Crystals. Volume 4. Wiley-VCH Verlag; 2014.

3. Chandrasekhar S. Discotic liquid crystals. A brief review. Liq Cryst. 1993;14:314. http://doi.org/10.1080/02678299308027301.

4. Reddy RA, Tschierske C. Bent-core liquid crystals: polar order, superstructural chirality and spontaneous desymmetrisation in soft matter systems. J Mater Chem. 2006;16:907-961. http://doi.org/10.1039/B504400F.

5. Takezoe H, Takanishi Y. Bent-Core Liquid Crystals: Their Mysterious and Attractive World. Jpn J Appl Phys 2006;45:597-625. http://doi.org/10.1143/JJAP.45.597.

6. Boden N, Bushby RJ, Cammidge AN, et al. The creation of long-lasting glassy columnar discotic liquid crystals using "dimeric" discogens. J Mater Chem. 1999;9:1391-1402. http://doi.org/10.1039/a810045d.

7. Diez S, Dunmur DA., de la Fuente MR, et al. Dielectric studies of a laterallylinked siloxane ester dimer. Liq Cryst. 2003;30:1021-1030. http://doi.org/10.1080/0267829031000152969.

8. Lagerwall JPF, Giesselmann F, Wand MD, et al. A chameleon chiral polar liquid crystal: rod-shaped when nematic, bent-shaped when smectic. Chem Mater. 2004;16:3606-3615. http://doi.org/10.1021/cm035294c.

9. Yelamaggad C V, Prasad SK, Nair GG, et al. A Low-Molar-Mass, Monodispersive, Bent-Rod Dimer Exhibiting Biaxial Nematic and Smectic A Phases. Angew Chem Int Ed 2004;43:3429-3432.

http://doi.org/10.1002/anie.200453908. 
10. Tamba MG, Kosata B, Pelz K, et al. Mesogenic dimers composed of a calamitic and a bent-core mesogenic unit. Soft Matter. 2006;2:60-65. http://doi.org/10.1039/b511140d.

11. Imrie CT, Henderson PA. Liquid crystal dimers and higher oligomers: between monomers and polymers. Chem Soc Rev 2007;36:2096. http://doi.org/10.1039/b714102e.

12. Tamba MG, Baumeister U, Pelzl G, et al. Banana-calamitic dimers: unexpected mesophase behaviour by variation of the direction of ester linking groups in the bent-core unit. Liq Cryst. 2010;37:853-874. http://doi.org/10.1080/02678291003798172.

13. Horčic M, Svoboda J, Seidler A, et al. W-shaped liquid crystalline dimers. RSC Adv. 2016;6:41972-41981. http://doi.org/10.1039/C6RA06268G.

14. Emsley JW, Luckhurst GR, Shilstone GN, et al. The Preparation and Properties of the $\alpha, \omega$-bis(4,4'-Cyanobiphenyloxy)Alkanes: Nematogenic Molecules with a Flexible Core. Mol Cryst Liq Cryst. 1984;102:223-233. http://doi.org/10.1080/01406568408070532.

15. Barnes PJ, Douglass AG, Heeks SK, et al. An enhanced odd-even effect of liquid crystal dimers: Orientational order in the $\alpha, \omega$-bis(4'-cyanobiphenyl-4-yl)alkanes. Liq Cryst. 1993;13:603-613. http://doi.org/10.1080/02678299308026332.

16. Ferrarini A, Luckhurst GR, Nordio PL, et al. Understanding the unusual transitional behaviour of liquid crystal dimers. Chem Phys Lett. 1993;214:409417. http://doi.org/10.1016/0009-2614(93)85658-B.

17. Morris SM, Clarke MJ, Blatch AE, et al. Structure-flexoelastic properties of bimesogenic liquid crystals. Phys Rev E. 2007;75:041701. http://doi.org/10.1103/PhysRevE.75.041701.

18. Atkinson KL, Morris SM, Castles F, et al. Flexoelectric and elastic coefficients of odd and even homologous bimesogens. Phys Rev E. 2012;85:12701. http://doi.org/10.1103/PhysRevE.85.012701.

19. Cestari M, Frezza E, Ferrarini A, et al. Crucial role of molecular curvature for the bend elastic and flexoelectric properties of liquid crystals: mesogenic dimers as a case study. J Mater Chem. 2011;21:12303-12308. http://doi.org/10.1039/C1JM12233A.

20. Imrie CT, Luckhurst GR. Liquid crystal dimers and oligomers. In: Goodby JW, Collings PJ, Kato T, Tschierske CJ, Gleeson H. y Raynes P. Handbook of Liquid Crsytals. Volume 7. Wiley-VCH Verlag; 2014.

21. Adlem K, Čopič M, Luckhurst GR, et al. Chemically induced twist-bend nematic liquid crystals, liquid crystal dimers, and negative elastic constants. Phys Rev E. 2013;88:22503. http://doi.org/10.1103/PhysRevE.88.022503.

22. Balachandran R, Panov VP, Vij JK, et al. Elastic properties of bimesogenic liquid crystals. Liq Cryst. 2013;40:681-688. http://doi.org/10.1080/02678292.2013.765973.

23. Borshch V, Kim Y-K, Xiang J, et al. Nematic twist-bend phase with nanoscale modulation of molecular orientation. Nat Commun. 2013;4:2635. http://doi.org/10.1038/ncomms3635. 
24. Sebastián N, López DO, Robles-Hernández B, et al. Dielectric, calorimetric and mesophase properties of 1'-(2',4-difluorobiphenyl-4'-yloxy)-9"-(4-

cyanobiphenyl-4'-yloxy) nonane: an odd liquid crystal dimer with a monotropic mesophase having the characteristics of a twist-bend nematic phase. Phys Chem Chem Phys. 2014;16:21391-21406. http://doi.org/10.1039/c4cp03462g.

25. Yun C-J, Vengatesan MR, Vij JK, et al. Hierarchical elasticity of bimesogenic liquid crystals with twist-bend nematic phase. Appl Phys Lett. 2015;106:173102. http://doi.org/10.1063/1.4919065.

26. Cestari M, Diez-Berart S, Dunmur DA, et al. Phase behavior and properties of the liquid-crystal dimer 1",7"-bis(4-cyanobiphenyl-4'-yl) heptane: A twist-bend nematic liquid crystal. Phys Rev E. 2011;84:031704. http://doi.org/10.1103/PhysRevE.84.031704.

27. Tripathi CSP, Losada-Pérez P, Glorieux C, et al. Nematic-nematic phase transition in the liquid crystal dimer $\mathrm{CBC}$ CB and its mixtures with 5CB: A high-resolution adiabatic scanning calorimetric study. Phys Rev E. 2011;84:41707. http://doi.org/10.1103/PhysRevE.84.041707.

28. Š Sepelj M, Lesac A, Baumeister U, et al. Intercalated liquid-crystalline phases formed by symmetric dimers with an $\alpha, \omega$-diiminoalkylene spacer. J Mater Chem. 2007;17:1154. http://doi.org/10.1039/b612517d.

29. Chen D, Porada JH, Hooper JB, et al. Chiral heliconical ground state of nanoscale pitch in a nematic liquid crystal of achiral molecular dimers. PNAS 2013;110:15931-15936. http://doi.org/10.1073/pnas.1314654110.

30. Memmer R. Liquid crystal phases of achiral banana-shaped molecules: a computer simulation study. Liq Cryst. 2002;29:483-496. http://doi.org/10.1080/02678290110104586.

31. Dozov I. On the spontaneous symmetry breaking in the mesophases of achiral banana-shaped molecules. Eur Lett. 2001;56:247. http://doi.org/10.1209/epl/i2001-00513-x.

32. Meyer C, Luckhurst GR, Dozov I. Flexoelectrically Driven Electroclinic Effect in the Twist-Bend Nematic Phase of Achiral Molecules with Bent Shapes. Phys Rev Lett. 2013;111:067801. http://doi.org/10.1103/PhysRevLett.111.067801.

33. Flory PJ. Statistical Mechanics of Chain Molecules. New York: WileyInterscience; 1969. .

34. Ferrarini A, Luckhurst GR, Nordio PL, et al. Prediction of the transitional properties of liquid crystal dimers. A molecular field calculation based on the surface tensor parametrization. J Chem Phys. 1994;100:1460. http://doi.org/10.1063/1.466625.

35. Ferrarini A, Luckhurst GR, Nordio PL. Even-odd effects in liquid crystal dimers with flexible spacers: a test of the rotational isomeric state approximation? Mol Phys. 1995;85:131-143. http://doi.org/10.1080/00268979500100991.

36. Ferrarini A, Luckhurst GR, Nordio PL, et al. Understanding the dependence of the transitional properties of liquid crystal dimers on their molecular geometry. Liq Cryst. 1996;21:373-382. http://doi.org/10.1080/02678299608032846.

37. Luckhurst GR. Liquid crystals: a chemical physicist's view. Liq Cryst. 2005;32:1335-1364. http://doi.org/10.1080/02678290500423128. 
38. Stocchero M, Ferrarini A, Moro GJ, et al. Molecular theory of dielectric relaxation in nematic dimers. J Chem Phys. 2004;121:8079. http://doi.org/10.1063/1.1794071.

39. Mandle RJ, Voll CCA, Lewis DJ, et al. Etheric bimesogens and the twist-bend nematic phase. Liq Cryst. 2016;43:13-21. http://doi.org/10.1080/02678292.2015.1091095.

40. Jansze SM, Martínez-Felipe A, Storey JMD, et al. A Twist-Bend Nematic Phase Driven by Hydrogen Bonding. Angew Chemie Int. Ed. 2015;54:643-646. http://doi.org/10.1002/anie.201409738.

41. Gorecka E, Vaupotič N, Zep A, et al. A Twist-Bend Nematic $\left(\mathrm{N}_{\mathrm{TB}}\right)$ Phase of Chiral Materials. Angew Chemie Int. Ed. 2015;54:10155-10159. http://doi.org/10.1002/anie.201502440.

42. Zep A, Aya S, Aihara K, et al. Multiple nematic phases observed in chiral mesogenic dimers. J Mater Chem. C 2013;1:46-49. http://doi.org/10.1039/C2TC00163B.

43. Dunmur DA, de la Fuente MR, Perez Jubindo MÁ, et al. Dielectric studies of liquid crystals: the influence of molecular shape. Liq Cryst. 2010;37:723-736. http://doi.org/10.1080/02678292.2010.484913.

44. Robles-Hernández B, Sebastián N, de la Fuente MR, et al. Twist, tilt, and orientational order at the nematic to twist-bend nematic phase transition of 1",9"bis(4-cyanobiphenyl-4'-yl) nonane: A dielectric, ${ }^{2} \mathrm{H}$ NMR, and calorimetric study. Phys Rev E. 2015;92:062505. http://doi.org/10.1103/PhysRevE.92.062505.

45. Hoffmann A, Vanakaras AG, Kohlmeier A, et al. On the structure of the Nx phase of symmetric dimers: inferences from NMR. Soft Matter. 2015;11:850855. http://doi.org/10.1039/c4sm02480j.

46. López DO, Sebastián N, de la Fuente MR, et al. Disentangling molecular motions involved in the glass transition of a twist-bend nematic liquid crystal through dielectric studies. J Chem Phys. 2012;137:034502. http://doi.org/10.1063/1.4733561.

47. López DO, Robles-Hernández B, Salud J, et al. Miscibility studies of two twistbend nematic liquid crystal dimers with different average molecular curvatures. A comparison between experimental data and predictions of a Landau mean-field theory for the $\mathrm{N}_{\mathrm{TB}}-\mathrm{N}$ phase transition. Phys Chem Chem Phys. 2016;18:43944404. http://doi.org/10.1039/C5CP07605F.

48. Robles-Hernández B, Sebastián N, Salud J, et al. Molecular dynamics of a binary mixture of twist-bend nematic liquid crystal dimers studied by dielectric spectroscopy. Phys Rev E. Forthcoming 2016.

49. Attard GS, Imrie CT, Karasz FE. Low molar mass liquid-crystalline glasses: preparation and properties of the $\alpha$-(4-cyanobiphenyl-4'-oxy)- $\omega$-(1pyreniminebenzylidene-4'-oxy)alkanes. Chem Mater. 1992;4:1246-1253. http://doi.org/10.1021/cm00024a025.

50. Sebastián N, López DO, Diez-Berart S, et al. Effect of Molecular Flexibility on the Nematic-to-Isotropic Phase Transition for Highly Biaxial Molecular NonSymmetric Liquid Crystal Dimers. Materials. 2011;4:1632-1647. 
http://doi.org/10.3390/ma4101632.

51. Sebastián N, de la Fuente MR, López DO, et al. Dielectric and Thermodynamic Study on the Liquid Crystal Dimer $\alpha$-(4-Cyanobiphenyl-4'-oxy)- $\omega-(1-$ pyreniminebenzylidene-4'-oxy)undecane (CBO11O-Py). J Phys.Chem B 2011;115:9766-9775. http://doi.org/10.1021/jp202796y.

52. Sebastián N, de la Fuente MR, López DO, et al. Overall dielectric study on the odd members of a highly nonsymmetric pyrene-based series of liquid crystal dimers. J Phys Chem B 2013;117:14486-14496.

http://doi.org/10.1021/jp406085r.

53. Diez-Berart S, López D, Salud J, et al. Two Glass Transitions Associated to Different Dynamic Disorders in the Nematic Glassy State of a Non-Symmetric Liquid Crystal Dimer Dopped with g-Alumina Nanoparticles. Materials. 2015;8:3334-3351. http://doi.org/10.3390/ma8063334.

54. Salud J, López DO, Sebastián N, et al. Influence of the chain length on the nematic-to-isotropic phase transition for the odd members of a highly nonsymmetric pyrene-based series of liquid crystal dimers. Liq Cryst. 2016;43:102111. http://doi.org/10.1080/02678292.2015.1066890.

55. Cestari M. Atomistic modelling of liquid crystal materials properties: a theoretical and computational methodology. Universita degli studi di Padova; 2008. .

56. Maier W, Meier G. Eine einfache theorie der dielektrischen eigenschaften homogen orientierter kristallinflussiger phasen des nematischen typs. Z. Naturforsch. 1961;16:262-267. .

57. Dunmur D a., Luckhurst GR, de la Fuente MR, et al. Dielectric relaxation in liquid crystalline dimers. J Chem Phys. 2001;115:8681-8691. http://doi.org/10.1063/1.1409365.

58. Nordio PL, Rigatti G, Segre U. Dielectric relaxation theory in nematic liquids. Mol Phys. 1973;25:129-136. http://doi.org/10.1080/00268977300100141.

59. Maier W, Saupe A. Eine einfache molecular-statistische theorie der nematischen kristallinflussigen phase. 1. Z. Naturforsch. 1959;14:882-889. .

60. Maier W, Saupe A. Eine einfache molecular-statistische theorie der nematischen kristallinflussigen phase. 2. Z. Naturforsch. 1960;15:287-292. .

61. Greco C, Luckhurst GR, Ferrarini A. Enantiotopic discrimination and director organization in the twist-bend nematic phase. Phys Chem Chem Phys. 2013;15:14961-14965. http://doi.org/10.1039/C3CP52222A.

62. Challa PK, Borshch V, Parri O, et al. Twist-bend nematic liquid crystals in high magnetic fields. Phys Rev E. 2014;89:060501. http://doi.org/10.1103/PhysRevE.89.060501.

63. Meyer C, Luckhurst GR, Dozov I. The temperature dependence of the heliconical tilt angle in the twist-bend nematic phase of the odd dimer CB7CB. J Mater Chem C. 2015;3:318-328. http://doi.org/10.1039/C4TC01927J.

64. Jokisaari JP, Luckhurst GR, Timimi BA, et al. Twist-bend nematic phase of the liquid crystal dimer CB7CB: orientational order and conical angle determined by 129 Xe and 2 H NMR spectroscopy. Liq Cryst. 2015;42:708-721. 
http://doi.org/10.1080/02678292.2015.1037576.

65. Urban S, Würflinger A. Relaxation Phenomena: Liquid Crystals, Magnetic Systems, Polymers, High-Tc Superconductors, Metallic Glasses. Haase W, Wróbel S, editors. Springer; 2003.

66. Ramou E, Ahmed Z, Welch C, et al. The stabilisation of the Nx phase in mixtures. Soft Matter. 2016;12:888-899. http://doi.org/10.1039/c5sm01961c.

67. Ribeiro de Almeida RR, Zhang C, Parri O, et al. Nanostructure and dielectric properties of a twist-bend nematic liquid crystal mixture. Liq Cryst. 2014;41:1661-1667. http://doi.org/10.1080/02678292.2014.947346. 
Figure 1: Energetically favoured molecular configuration for even and odd dimers within the RIS model having a tetrahedral geometry: trans configuration (left) and cis configuration (right).

Figure 2: Chemical structures and transition temperatures as found from dielectric measurements performed on cooling for the main materials that are considered in the present review.

Figure 3. The temperature dependence of the static permittivity reduced by the permittivity value at the isotropic phase $\varepsilon_{i s o}\left(T_{N I}\right)(\diamond)$ CBO7O.Py, $(\nabla)$ FFO9OCB and ( $)$ CB9CB. Dashed lines indicate the $\mathrm{N}-\mathrm{N}_{\mathrm{TB}}$ transition for CB9CB.

Figure 4. a) The dependence on the shifted temperature of the tatic permittivity reduced by the permittivity value at the isotropic phase $\varepsilon_{i s o}\left(T_{N I}\right)$. Dashed lines indicate the N$\mathrm{N}_{\mathrm{TB}}$ transition. b) The dependence on the shifted temperature of the splay (full symbols) and bend (empty symbols) elastic constants in the nematic phase. (०) $\mathrm{CB} 9 \mathrm{CB},(\triangle)$ CB7CB and ( $\square)$ the mixture CB7CB + CB9CB (0.46).

Figure 5. The dependence on the shifted temperature of the static permittivity reduced by the permittivity value at the isotropic phase $\varepsilon_{i s o}\left(T_{N I}\right)$ for $(\boldsymbol{\nabla})$ FFO9OCB and ( $\left.\square\right)$ FFO10OCB.

Figure 6. Schematic representation of Stocchero et al.'s [38] four-state model for the reorientation dynamics of a dimeric mesogen subject to a nematic potential. Terminal rigid groups can be equal or different, polar or non-polar. States a and d correspond to trans configuration, while $\mathrm{c}$ and $\mathrm{b}$ are the cis conformers.

Figure 7. (Coluor online) CB7CB. Three-dimensional plot of the dielectric losses vs the temperature and the logarithm of the frequency for the a) homeotropic and b) parallel alignments of CB7CB [46].

Figure 8. (Color online) a) Dielectric strength of the relaxation modes vs. temperature for CBO5O.Py. b) Arrhenius plot of the characteristic relaxation frequencies.

$(\diamond) m_{1, L \|}(\square) m_{1, H \|}(\triangle) m_{2 \|},(\odot) m_{1 H}$ and $(\nabla) m_{1 L} \cdot[52]$ 
Figure 9. (Colour online) Frequency and temperature dependence of the parallel dielectric losses of FFO10OCB. Dashed lines are given as guides to the eye.

Figure 10. (Colour online). Frequency dependence of the real (full symbols) and imaginary (empty symbols) dielectric permittivity of FFO10OCB in the nematic phase $\left(\mathrm{T}=120^{\circ} \mathrm{C}\right)$. Solid lines are the resulting fit to Equation (1) and the corresponding deconvolution into the elementary processes. Although the direct current conductivity is considered in the fit, for simplicity its contribution in not drawn.

Figure 11. (Colour online) Dielectric strength of the relaxation modes vs. the shifted temperature for FFO10OCB (full symbols) and FFO9OCB (empty symbols): $(\diamond \diamond) m_{1, L \|}$ $(\square \square) m_{1, H \|}(\triangle \mathbf{\Lambda}) m_{2 \|}$ and $(\circ \bullet) m_{1}$.

Figure 12. (Colour online) Arrhenius plot of the frequencies of the relaxation modes for FFO10OCB (full symbols) and FFO9OCB (empty symbols): $(\diamond \diamond) m_{1, L \|}(\square \square) m_{1, H \|}$ $(\triangle \mathbf{\Lambda}) m_{2 \|}$ and $(\circ \bullet) m_{1}$. 


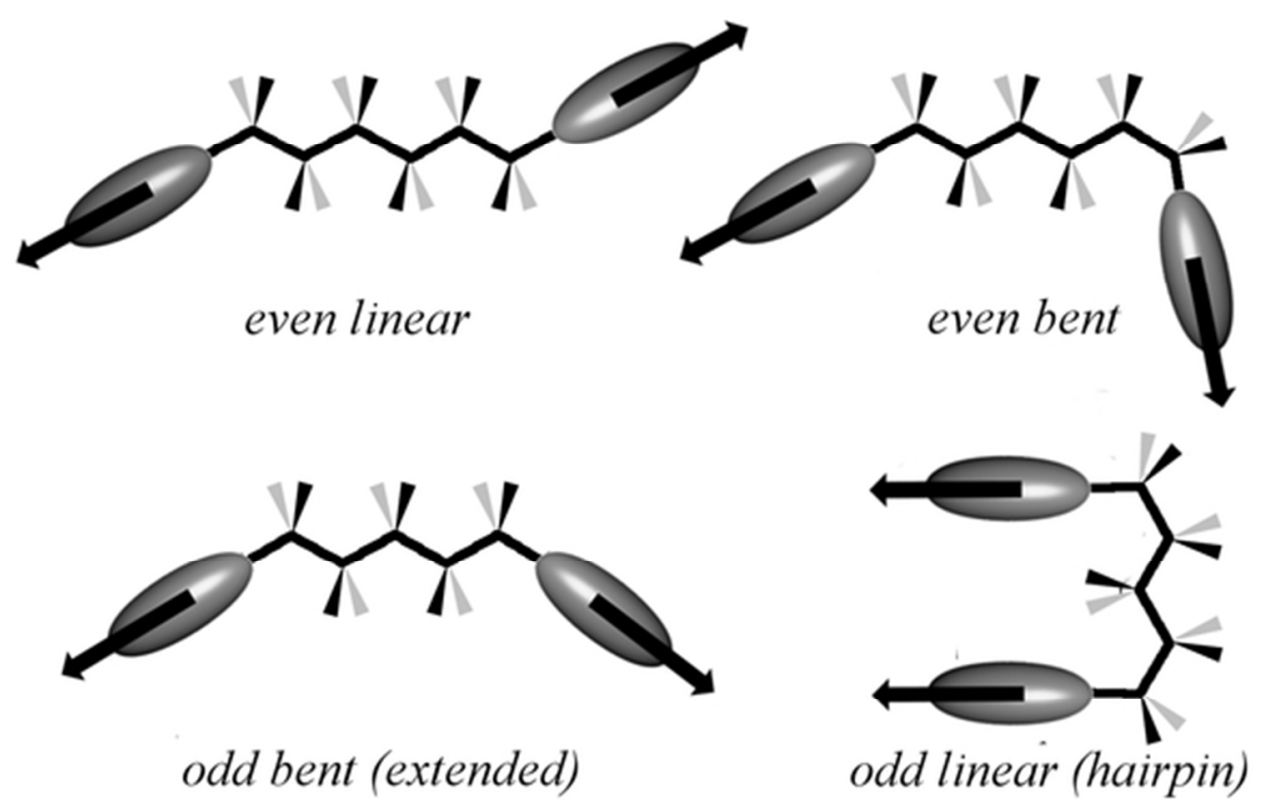

Figure 1: Energetically favoured molecular configuration for even and odd dimers within the RIS model having a tetrahedral geometry: trans configuration (left) and cis configuration (right). $51 \times 32 \mathrm{~mm}(300 \times 300 \mathrm{DPI})$ 


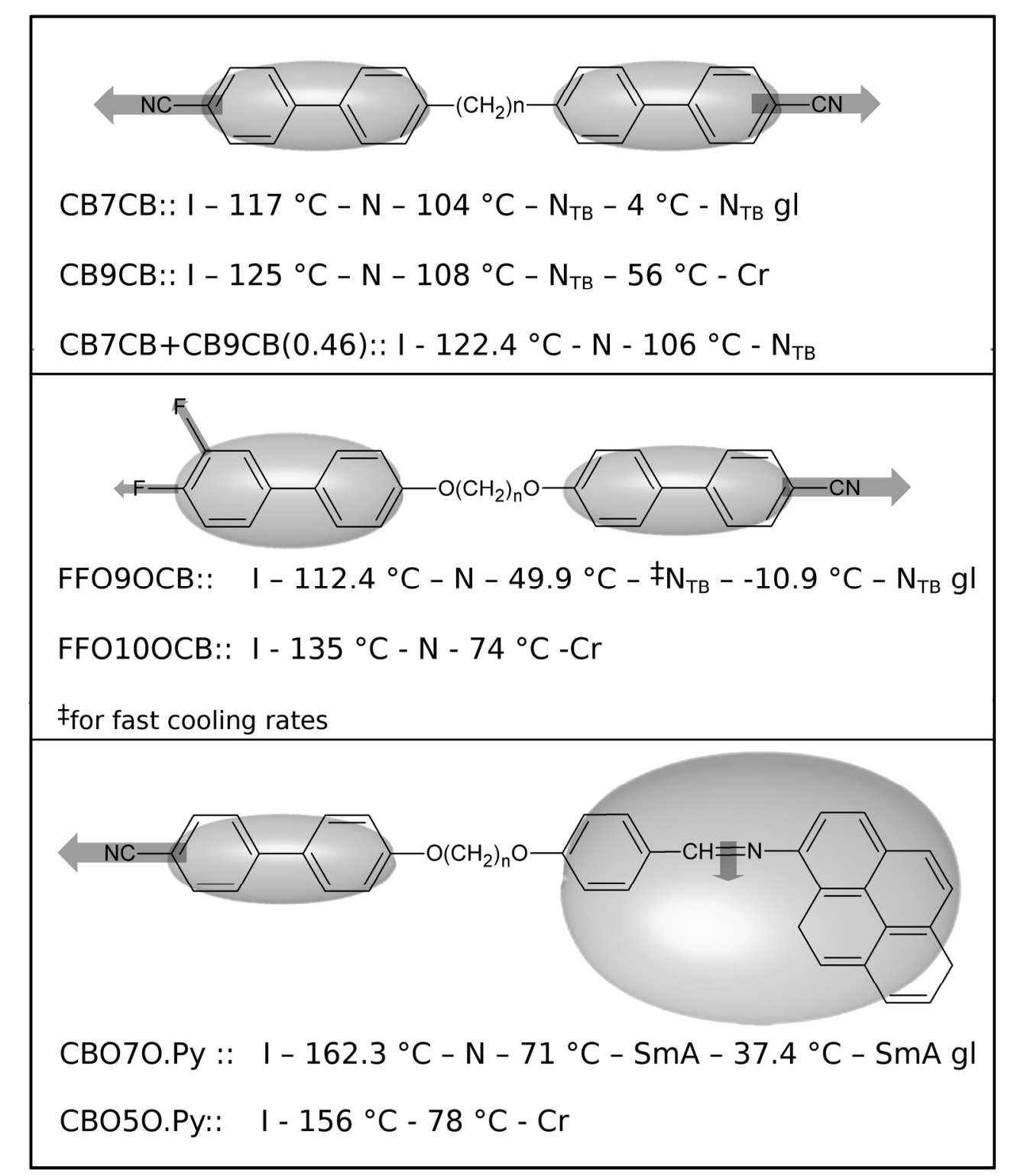

Figure 2: Chemical structures and transition temperatures as found from dielectric measurements performed on cooling for the main materials that are considered in the present review. $190 \times 227 \mathrm{~mm}(300 \times 300 \mathrm{DPI})$ 


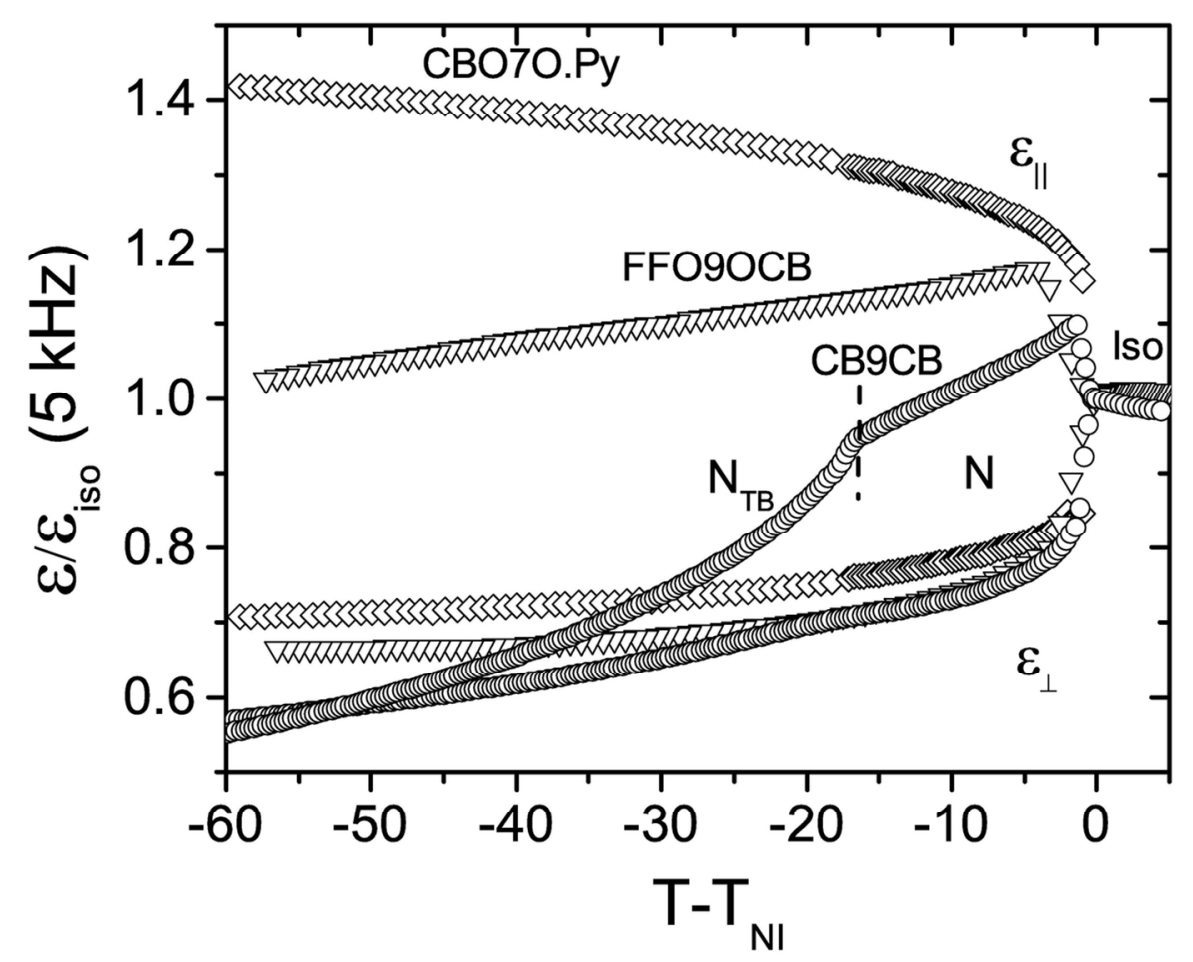

Figure 3. The temperature dependence of the static permittivity reduced by the permittivity value at the isotropic phase $\varepsilon_{i s o}(T)_{\mathrm{NI}}$ (diamonds) CBO7O.Py, (triangles) FFO9OCB and (circles) CB9CB. Dashed lines indicate the $\mathrm{N}-\mathrm{N}_{\mathrm{TB}}$ transition for $\mathrm{CB} 9 \mathrm{CB}$. $120 \times 90 \mathrm{~mm}(300 \times 300$ DPI $)$ 


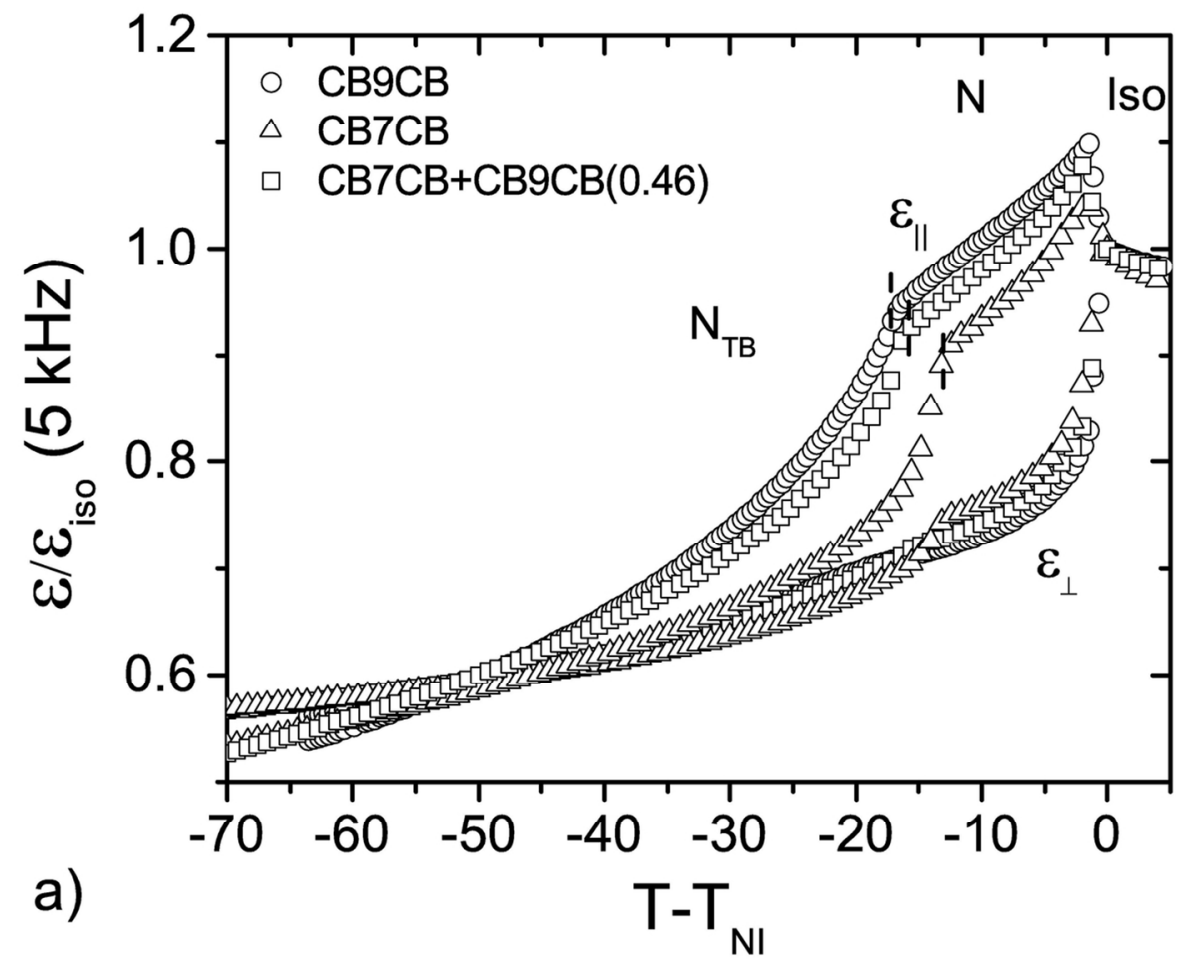

Figure 4. a) The dependence on the shifted temperature of the tatic permittivity reduced by the permittivity value at the isotropic phase $\varepsilon_{\text {iso }}\left(\mathrm{T}_{\mathrm{NI}}\right)$. Dashed lines indicate the $\mathrm{N}-\mathrm{N}_{\mathrm{TB}}$ transition. (circles) $\mathrm{CB} 9 \mathrm{CB}$, (triangles) $\mathrm{CB7CB}$ and (squares) the mixture $\mathrm{CB7CB}+\mathrm{CB} 9 \mathrm{CB}(0.46)$. $120 \times 90 \mathrm{~mm}(300 \times 300 \mathrm{DPI})$ 
Figure 4. b) The dependence on the shifted temperature of the splay (full symbols) and bend (empty symbols) elastic constants in the nematic phase. (circles) $C B 9 C B$, (triangles) CB7CB and (squares) the mixture $\mathrm{CB7CB}+\mathrm{CB} 9 \mathrm{CB}(0.46)$. $120 \times 90 \mathrm{~mm}(300 \times 300 \mathrm{DPI})$ 


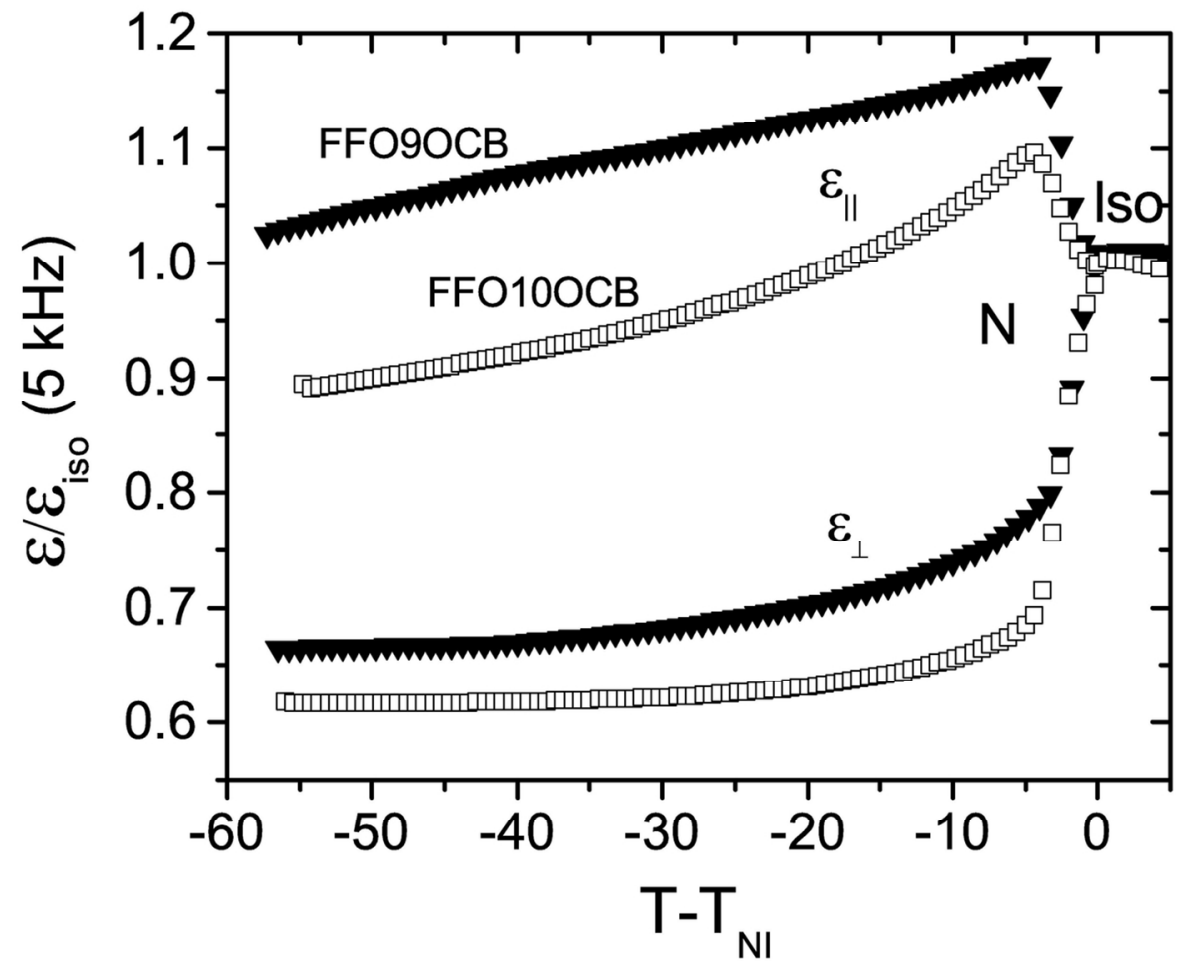

Figure 5. The dependence on the shifted temperature of the static permittivity reduced by the permittivity value at the isotropic phase $\varepsilon_{\text {iso }}\left(T_{\mathrm{NI}}\right)$ for (triangles) FFO9OCB and (squares) FFO100CB. $120 \times 90 \mathrm{~mm}(300 \times 300 \mathrm{DPI})$ 
Figure 6. Schematic representation of Stocchero et al.'s [38] four-state model for the reorientation dynamics of a dimeric mesogen subject to a nematic potential. Terminal rigid groups can be equal or different, polar or non-polar. States a and d correspond to trans configuration, while $\mathrm{c}$ and $\mathrm{b}$ are the cis conformers. $97 \times 87 \mathrm{~mm}(300 \times 300 \mathrm{DPI})$ 

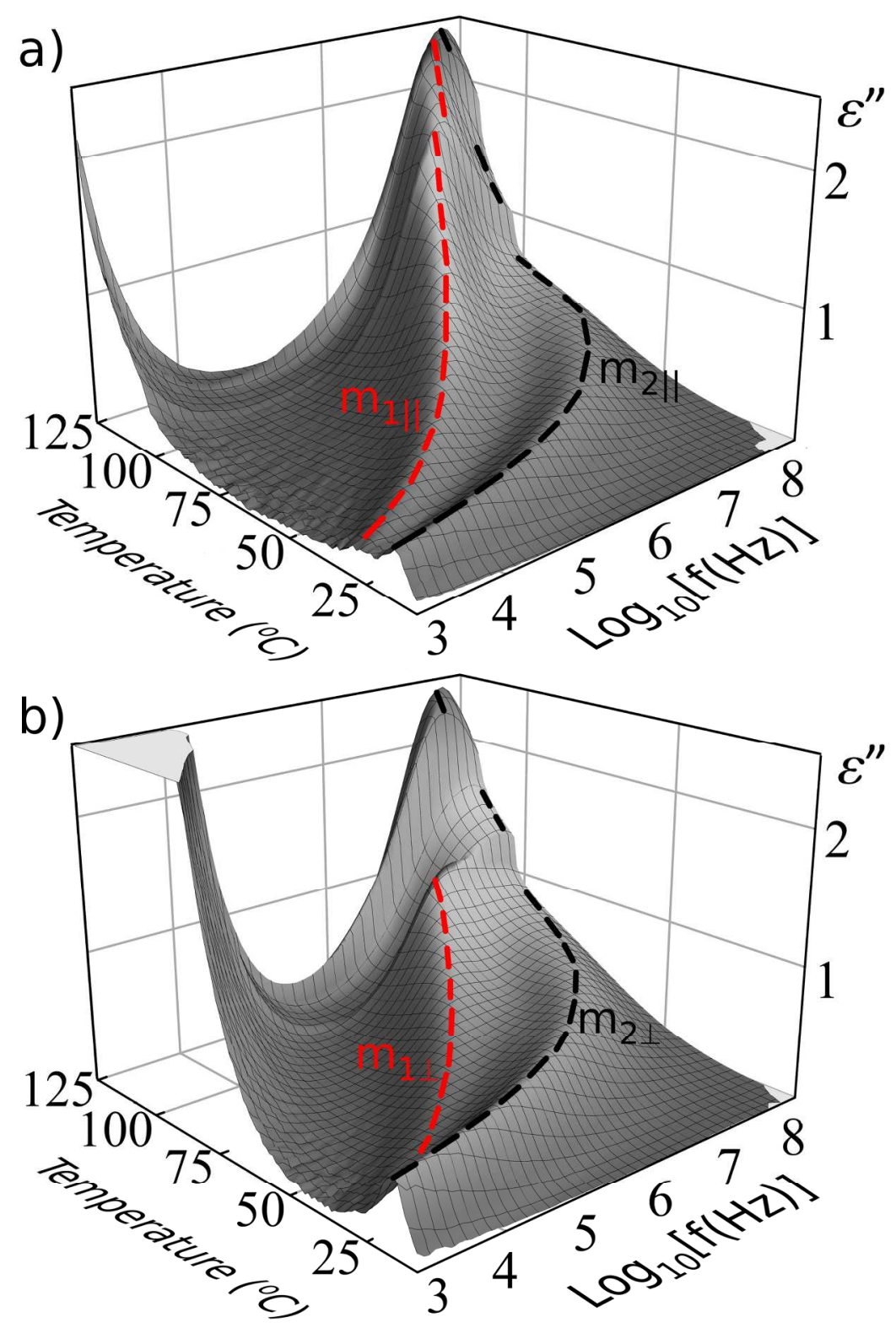

Figure 7. (Coluor online) CB7CB. Three-dimensional plot of the dielectric losses vs the temperature and the logarithm of the frequency for the a) homeotropic and b) parallel alignments of CB7CB [46]. $166 \times 249 \mathrm{~mm}(300 \times 300 \mathrm{DPI})$ 


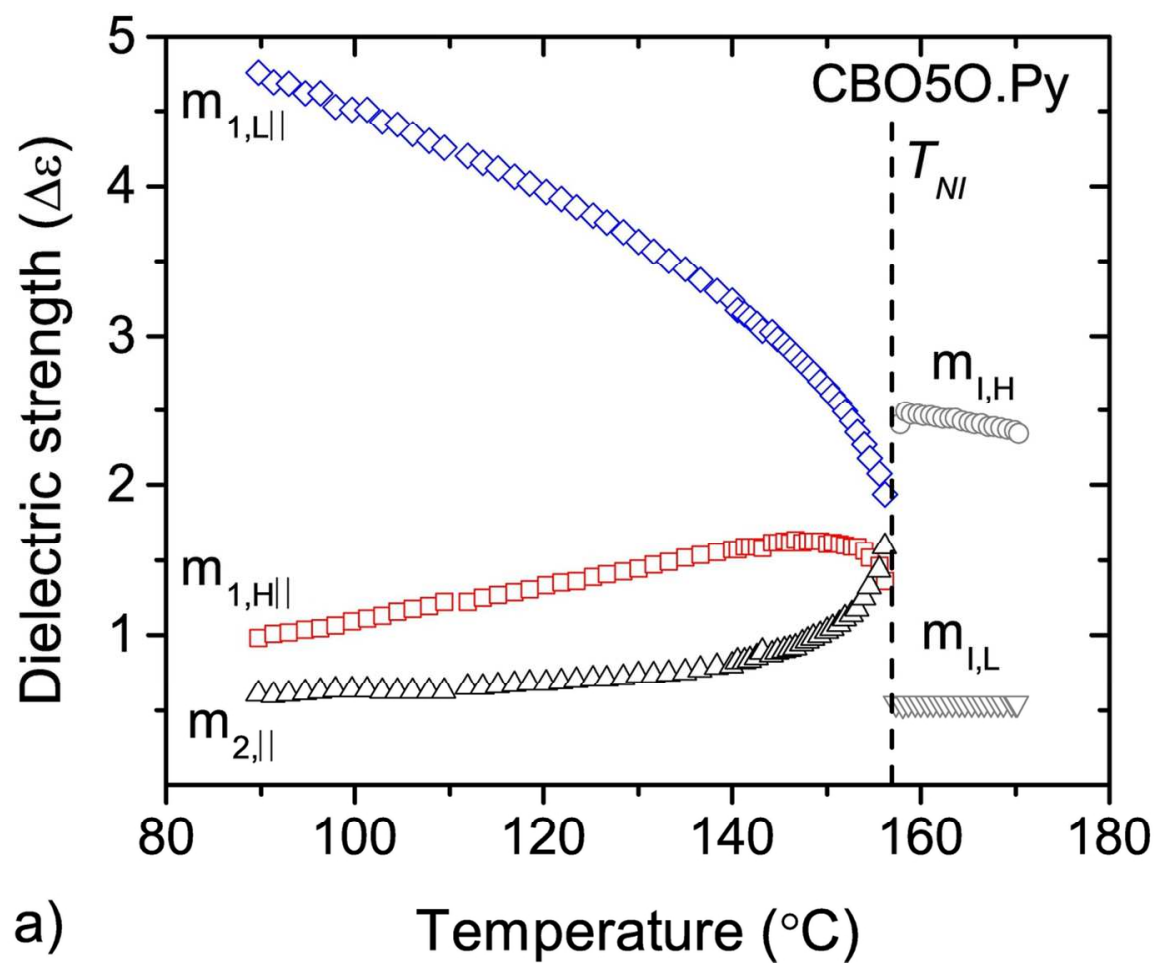

Figure 8. (Color online) a) Dielectric strength of the relaxation modes vs. temperature for CBO5O.Py. (diamonds) $m_{1, L I l}$, (squares) $m_{1, H \|}$, (up-triangles) $m_{2 \|}$, (circles) $m_{1 H}$ and (down-triangles) $m_{1 L}$. [52] $120 \times 90 \mathrm{~mm}(300 \times 300 \mathrm{DPI})$ 


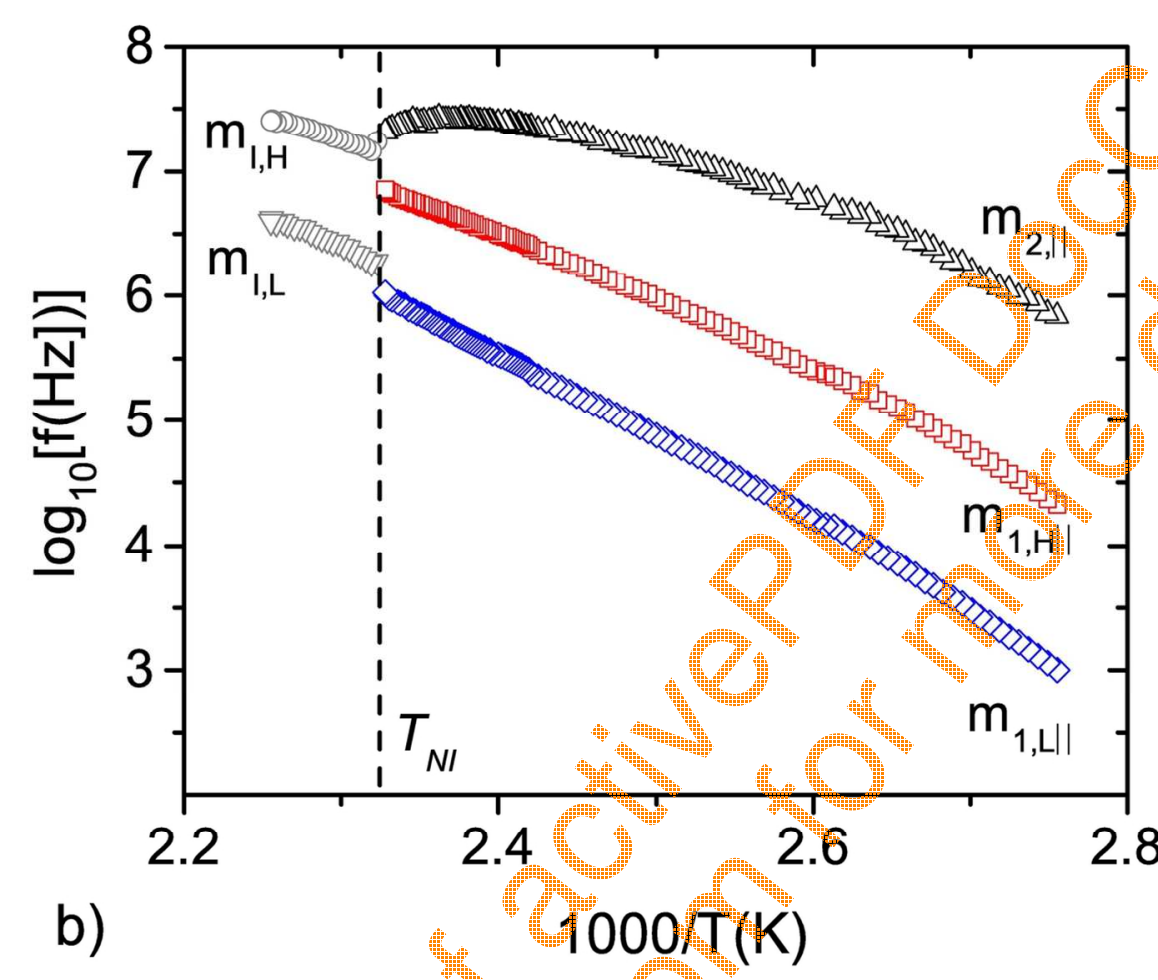

Figure 8. (Color online) b) Arrhenius plot of the characteristic relaxation frequencies for CBO5O.Py. (diamonds) $\mathrm{m}_{1, \mathrm{~L} \mid \mathrm{l}}$, (squares) $\mathrm{m}_{1, \mathrm{H} ! \mathrm{l}}$ (up-triangles) $\mathrm{m}_{2 \mid \mathrm{l}}$, (circles) $\mathrm{m}_{1 \mathrm{H}}$ and (down-triangles) $\mathrm{m}_{1 \mathrm{~L}}$. [52] $120 \times 90 \mathrm{~mm}(300 \times 300 \mathrm{DPI})$ 


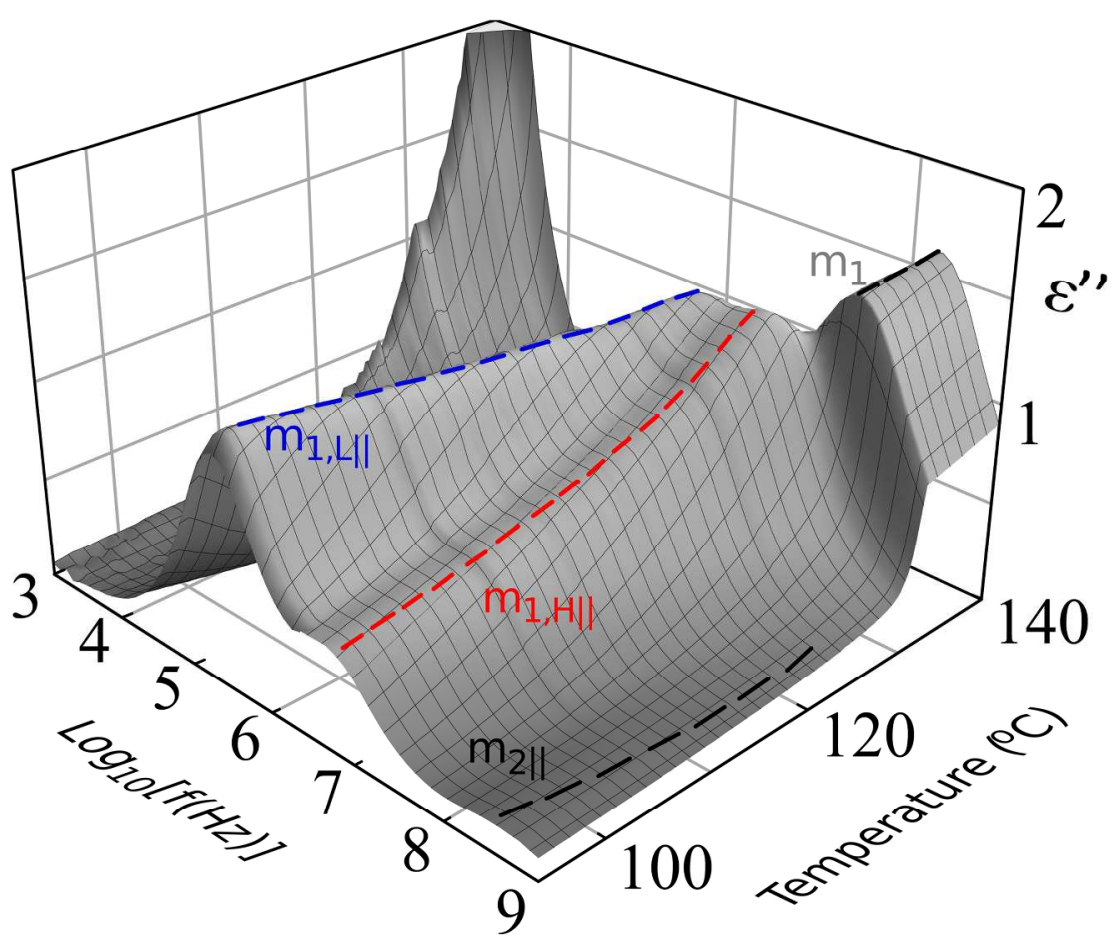

Figure 9. (Colour online) Frequency and temperature dependence of the parallel dielectric losses of FFO10OCB. Dashed lines are given as guides to the eye. $209 \times 148 \mathrm{~mm}(300 \times 300 \mathrm{DPI})$ 


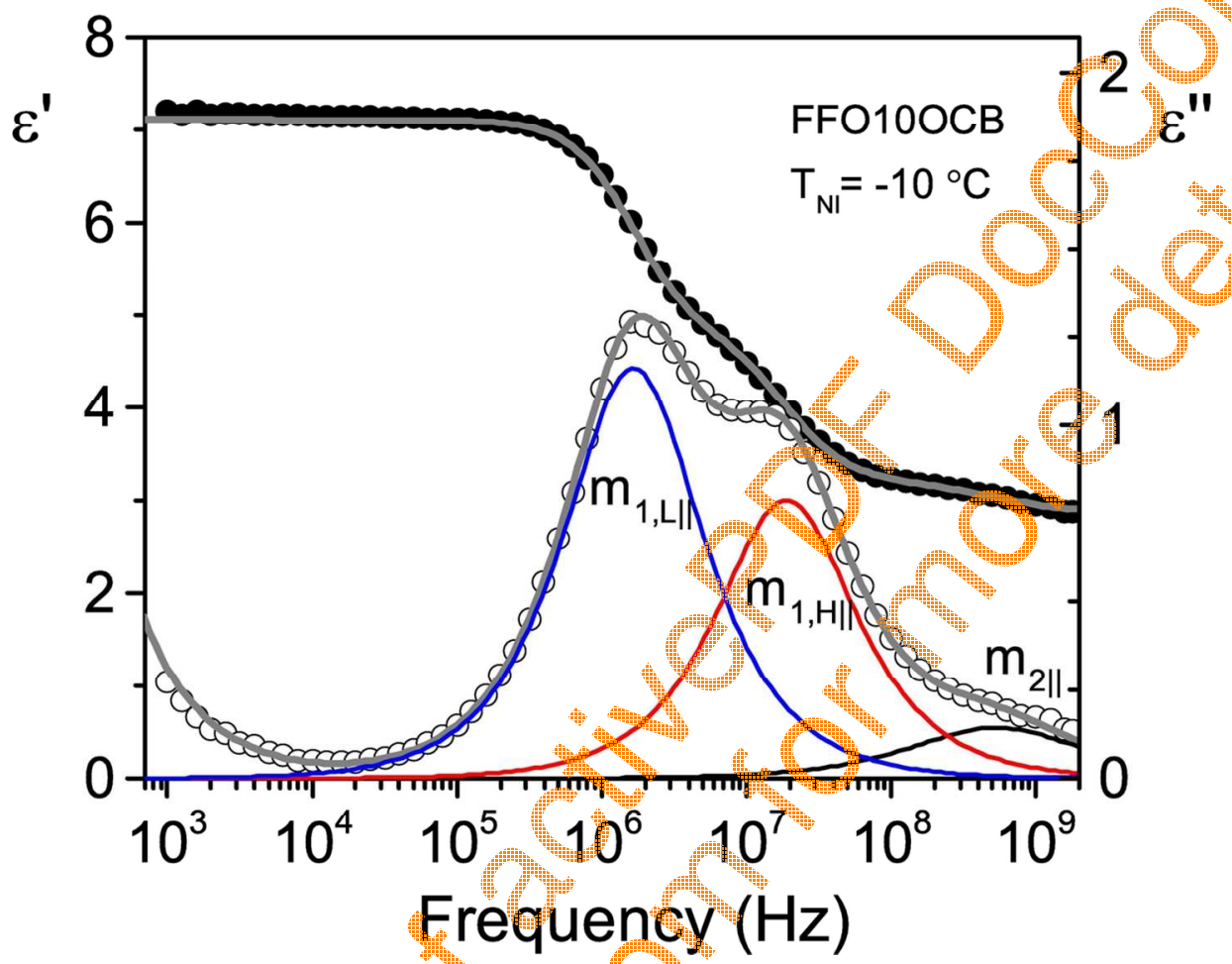

Figure 10. (Colour online). Frequency dependence of the real (full symbols) and imaginary (empty symbols) dielectric permittivity of FFO10OCB in the nematic phase $\left(T=120^{\circ} \mathrm{C}\right)$. Solid lines are the resulting fit to Equation (1) and the corresponding deconvolution into the elementary processes. Although the direct current conductivity is considered in the fit, for simplicity its contribution in not drawn. $120 \times 90 \mathrm{~mm}(300 \times 300 \mathrm{DPI})$ 


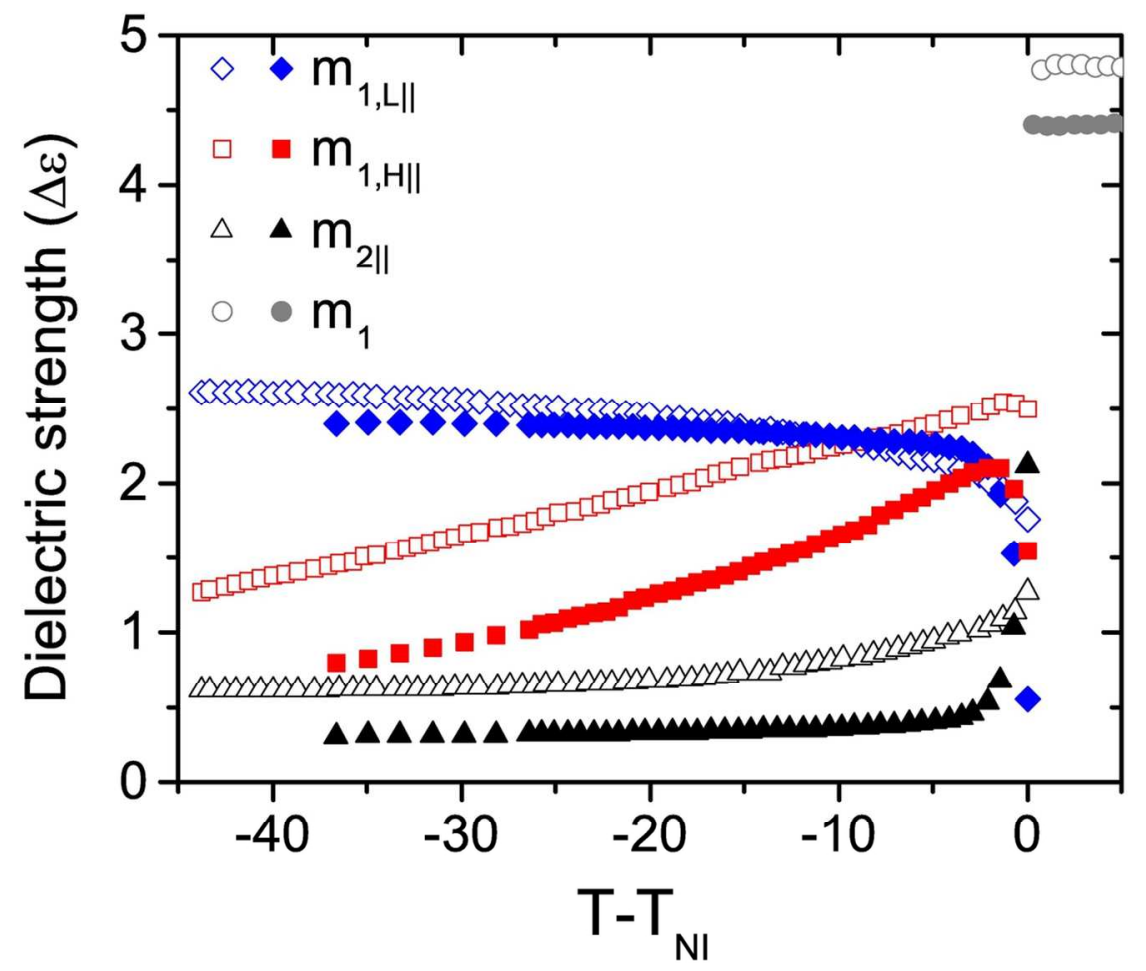

Figure 11. (Colour online) Dielectric strength of the relaxation modes vs. the shifted temperature for FFO10OCB (full symbols) and FFO9OCB (empty symbols): (diamonds) $m_{1, L l l}$, (squares) $m_{1, H \| l}$, (triangles) $\mathrm{m}_{2 \|}$ and (circles) $\mathrm{m}_{1}$. $120 \times 90 \mathrm{~mm}(300 \times 300 \mathrm{DPI})$ 


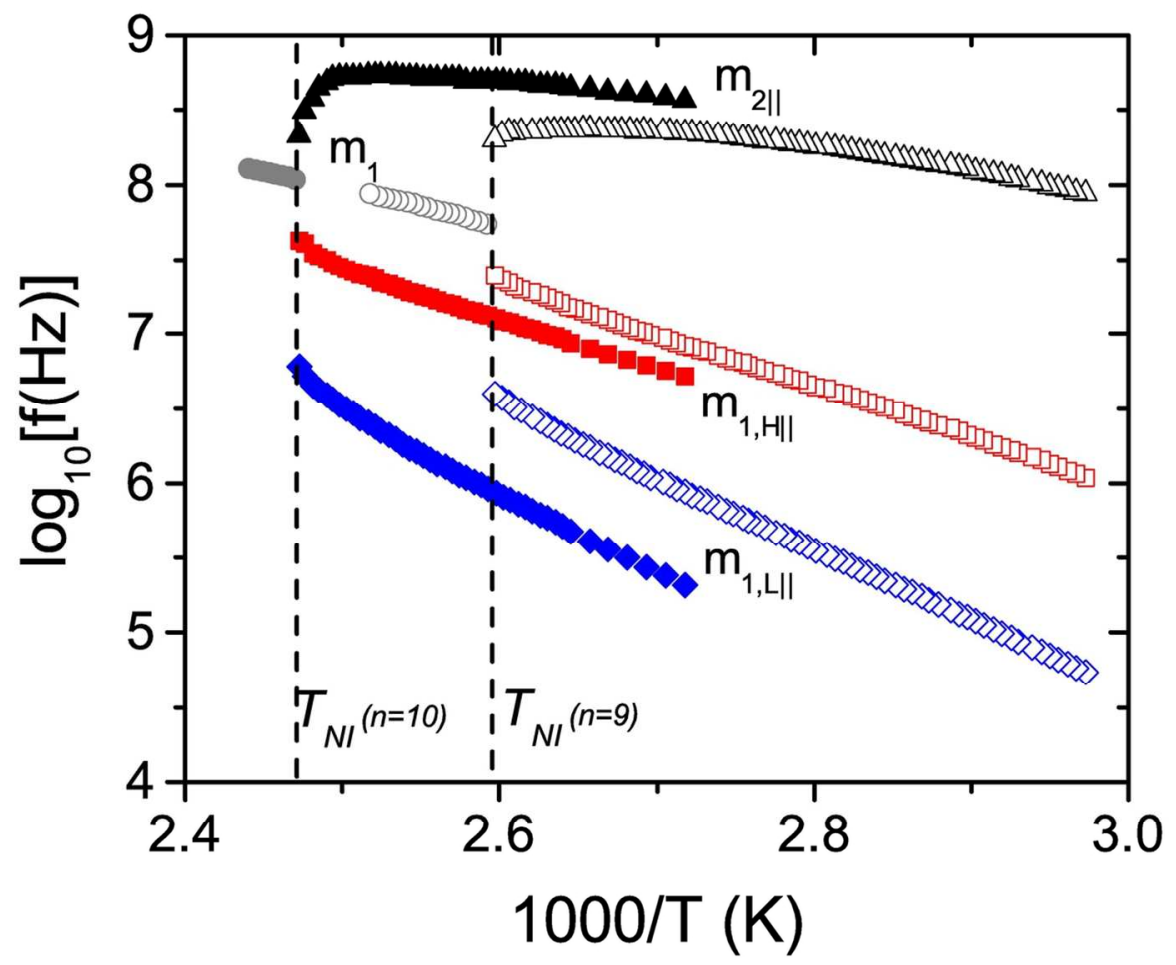

Figure 12. (Colour online) Arrhenius plot of the frequencies of the relaxation modes for FFO100CB (full symbols) and FFO9OCB (empty symbols): (diamonds) $m_{1, L I I}$, (squares) $m_{1, H \| l}$, (triangles) $m_{2 \|}$ and (circles) $m_{1}$. $120 \times 90 \mathrm{~mm}(300 \times 300$ DPI $)$ 